Article

\title{
Playing with Opening and Closing of Heterocycles: Using the Cusmano-Ruccia Reaction to Develop a Novel Class of Oxadiazolothiazinones, Active as Calcium Channel Modulators and P-Glycoprotein Inhibitors
}

Domenico Spinelli ${ }^{1}$, Roberta Budriesi ${ }^{2, *}$, Barbara Cosimelli ${ }^{3}$, Elda Severi ${ }^{3}$, Matteo Micucci ${ }^{2}$, Massimo Baroni ${ }^{4}$, Fabio Fusi ${ }^{5}$, Pierfranco Ioan ${ }^{2}$, Simon Cross ${ }^{4}$, Maria Frosini ${ }^{5}$, Simona Saponara ${ }^{5}$, Rosanna Matucci ${ }^{6}$, Camillo Rosano ${ }^{7}$, Maurizio Viale ${ }^{8}$, Alberto Chiarini ${ }^{2}$ and Emanuele Carosati ${ }^{9, *}$

1 Dipartimento di Chimica “G. Ciamician”, Alma Mater Studiorum-Università di Bologna, Via F. Selmi 2, Bologna 40126, Italy; E-Mail: domenico.spinelli@unibo.it

2 Dipartimento di Farmacia e Biotecnologie, Alma Mater Studiorum-Università di Bologna, Via Belmeloro 6, Bologna 40126, Italy; E-Mails: matteo.micucci2@unibo.it (M.M.); pierfranco.ioan3@unibo.it (P.I.); alberto.chiarini@unibo.it (A.C.)

3 Dipartimento di Farmacia, Università di Napoli "Federico II", Via D. Montesano 49, Napoli 80131, Italy; E-Mails: barbara.cosimelli@unina.it (B.C.); elda.severi@unina.it (E.S.)

4 Molecular Discovery Ltd., 215 Marsh Road, Pinner, Middlesex HA5 5NE, UK; E-Mails: massimo@moldiscovery.com (M.B.); simon@moldiscovery.com (S.C.)

5 Dipartimento di Scienze della Vita, Università degli Studi di Siena, Via A. Moro 2, Siena 53100, Italy; E-Mails: fabio.fusi@unisi.it (F.F.); maria.frosini@unisi.it (M.F.); simona.saponara@unisi.it (S.S.)

6 Dipartimento di Neuroscienze, Area del Farmaco e Salute del Bambino (NEUROFARBA) Viale Pieraccini 6, Firenze 50139, Italy; E-Mail: rosanna.matucci@unifi.it

7 IRCCS Azienda Ospedaliera Universitaria San Martino-IST Istituto Nazionale per la Ricerca sul Cancro, U.O.S. Biopolimeri e Proteomica, L.go R. Benzi, 10, Genova 16132, Italy;

E-Mail: camillo.rosano@istge.it

8 IRCCS Azienda Ospedaliera Universitaria San Martino-IST Istituto Nazionale per la Ricerca sul Cancro, U.O.C. Bioterapie, L.go R. Benzi, 10, Genova 16132, Italy;

E-Mail: maurizio.viale@istge.it

9 Dipartimento di Chimica, Biologia e Biotecnologie, Università di Perugia, Via Elce di Sotto 10, Perugia 06123, Italy

* Authors to whom correspondence should be addressed; E-Mails: roberta.budriesi@unibo.it (R.B.); emanuele@chemiome.chm.unipg.it (E.C.); Tel.: +39-(0)51-2099-737 (R.B.); +39-(0)75-585-5550 (E.C.); Fax: +39-(0)75-45646 (E.C.). 
External Editors: Iwao Ojima and Robert C. Rizzo

Received: 20 June 2014; in revised form: 15 August 2014 / Accepted: 4 September 2014 /

Published: 14 October 2014

\begin{abstract}
As a result of the ring-into-ring conversion of nitrosoimidazole derivatives, we obtained a molecular scaffold that, when properly decorated, is able to decrease inotropy by blocking L-type calcium channels. Previously, we used this scaffold to develop a quantitative structure-activity relationship (QSAR) model, and we used the most potent oxadiazolothiazinone as a template for ligand-based virtual screening. Here, we enlarge the diversity of chemical decorations, present the synthesis and in vitro data for 11 new derivatives, and develop a new 3D-QSAR model with recent in silico techniques. We observed a key role played by the oxadiazolone moiety: given the presence of positively charged calcium ions in the transmembrane channel protein, we hypothesize the formation of a ternary complex between the oxadiazolothiazinone, the $\mathrm{Ca}^{2+}$ ion and the protein. We have supported this hypothesis by means of pharmacophore generation and through the docking of the pharmacophore into a homology model of the protein. We also studied with docking experiments the interaction with a homology model of P-glycoprotein, which is inhibited by this series of molecules, and provided further evidence toward the relevance of this scaffold in biological interactions.
\end{abstract}

Keywords: 3D-QSAR; docking; Fingerprints for Ligands and Proteins (FLAP); L-Type Calcium Channels (LTCC); multidrug resistance (MDR1); negative inotropic activity; oxadiazolothiazinones; pharmacophore modeling; ternary complex

\title{
1. Introduction
}

Ring-into-ring conversions are basically ring transformations of heterocycles and constitute an interesting area for mechanistic studies and synthetic design [1-4]. The presence of heteroatom(s) favors the opening process, which yields the creation of new interesting functional groups that may even react to form new heterocycles [5,6]. Given the wide applicability domain of heterocyclic molecules, ranging from pharmaceuticals to herbicides, from veterinary to material chemistry [7], they have been jokingly named "jewelry rings studded with precious stones", with the role of the precious stones being played by the heteroatoms [7].

The presence of heteroatom(s) in the ring causes a lowering of the resonance stabilization energy (particularly significant in five-membered rings), and introduces electronegativity differences between atoms of the ring $[8,9]$. These factors play a role in the ring-opening process of the carbon-heteroatom or heteroatom-heteroatom bonds, thus affecting the course and the final products of the reaction.

In this paper, we focus on some reactions of heterocycles, with special attention on the ring-into-ring conversion of nitrosoimidazole derivatives. One of these reactions led to a class of molecules, the 
oxadiazolo[3,4-c][1,4]thiazin-3-ones [10], biologically active against L-type calcium channels (LTCC) [11,12], and P-glycoprotein 1 (P-gp, or ATP-binding cassette sub-family B member 1, abbreviated as ABCB1) [13,14].

The synthetic design of oxadiazolothiazinones began by observing the difference between 2,5-diphenylimidazole (1), stable to acids in ethanol at room temperature as well as at reflux, and 4-nitroso-2,5-diphenylimidazole (2), that reacts with mineral acids at room temperature (Scheme 1) [15,16]. The ring-opening/ring-closing reaction, that gives 3-benzoyl-5-phenyl-1,2,4oxadiazole (3), was named as the "Cusmano-Ruccia reaction" [17].

Scheme 1. Difference between imidazole and nitrosoimidazole; the latter reacts with hydrochloric acid according to the "Cusmano-Ruccia reaction" mechanism.
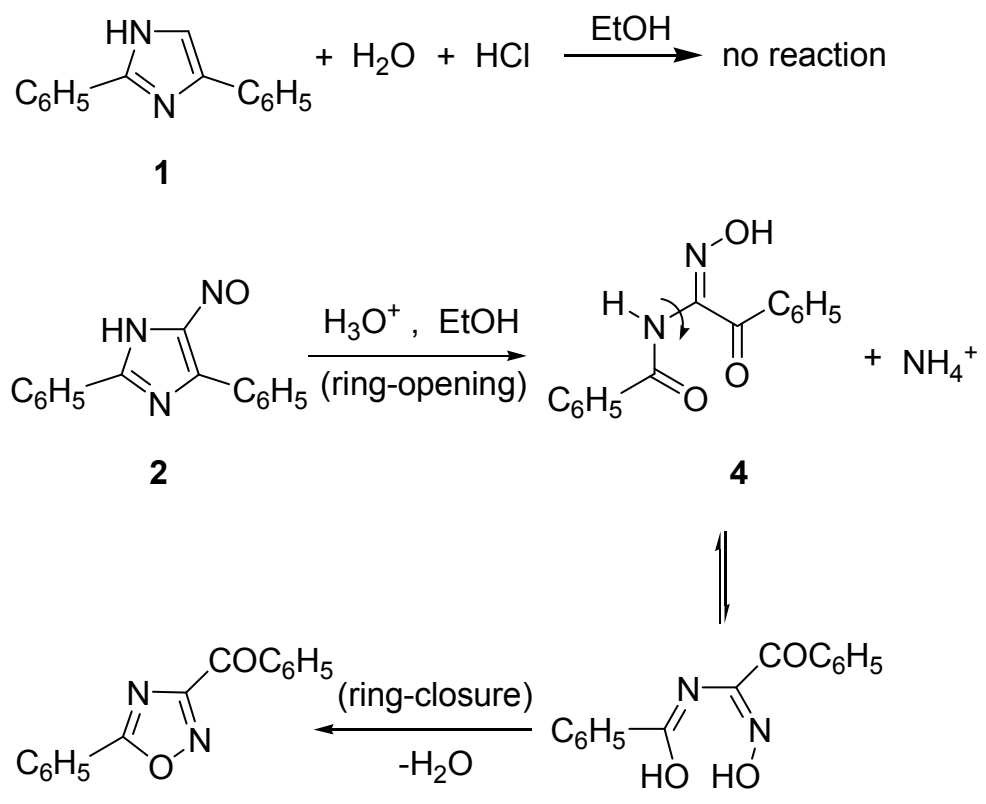

3

5

By extending the study of the reactivity to condensed systems, we observed that 5-nitrosoimidazo[2,1-b][1,3]thiazoles also react easily with hydrochloric acid [10,18-20]. Thus, 3-methyl-5nitroso-6-(4-chlorophenyl)imidazo[2,1-b][1,3]thiazole (6) (Scheme 2a) gives 5-methyl-8-chlorophenyl-8-hydroxy-8H-[1,2,4] oxadiazolo[3,4-c][1,4]thiazin-3-one (7) $[10,18]$.

We have also investigated the reactivity of 6-(4-chlorophenyl)-3-methyl-5-nitrosoimidazo[2,1b][1,3] oxazole (11) [21], which gives the 3-(4-chlorobenzoyl)-5-methyl-1,2,4-oxadiazole (12) (Scheme 2b). In the case of imidazopyrimidines, the reaction leads to the 4-amino-1,2,4-oxadiazoles 17 (Scheme 2c) [22]; in contrast, a simple denitrosation occurs in the case of the imidazopyridines (Scheme 2d) [22].

By extending the abovementioned Cusmano-Ruccia reaction to several 5-nitroso-6-arylimidazo[2,1$b][1,3]$ thiazoles $[19,20]$, we obtained a library of $[1,2,4]$ oxadiazolo[3,4-c][1,4]thiazinones. Given the resemblance to diltiazem (24) [23], a well-known calcium channel blocker that has important therapeutic applications (angina pectoris, supraventricular arrhythmias, and mild to moderate systemic hypertension) [24,25], we hypothesized for these molecules a similar biological effect; thus, we investigated this experimentally, with functional assays, electrophysiology and binding experiments. 
Scheme 2. Mechanisms for different nitrosoimidazoles, condensed with thiazole (a), oxazole (b), pyrimidine (c) and pyridine (d). $A r$ stands for para-chlorophenyl.

(a)

isolated intermediate (at r.t.)

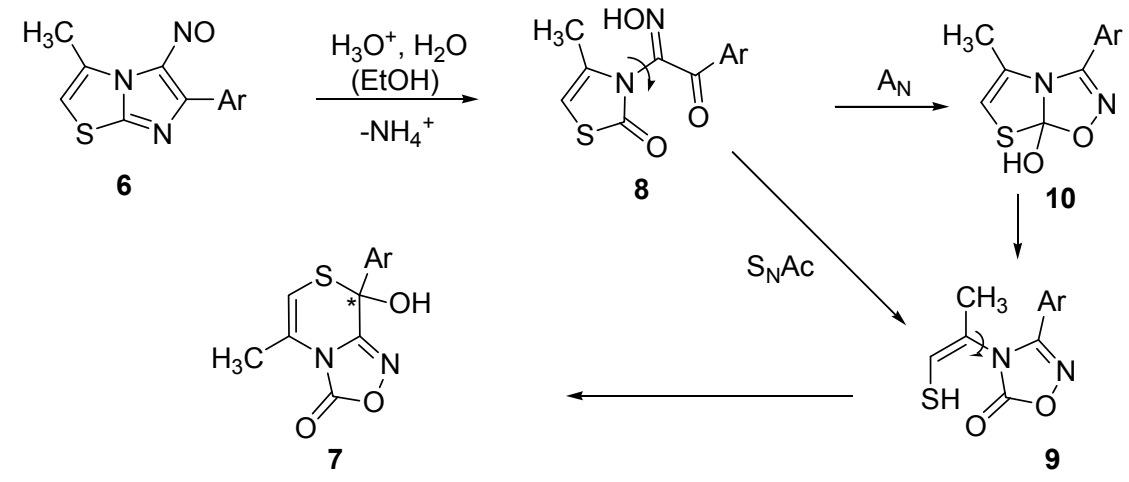

(b)

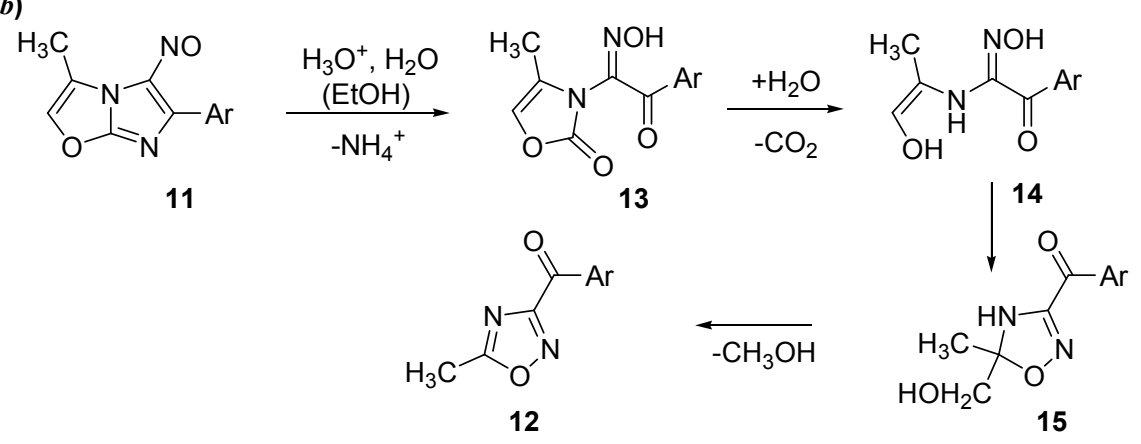

(c)
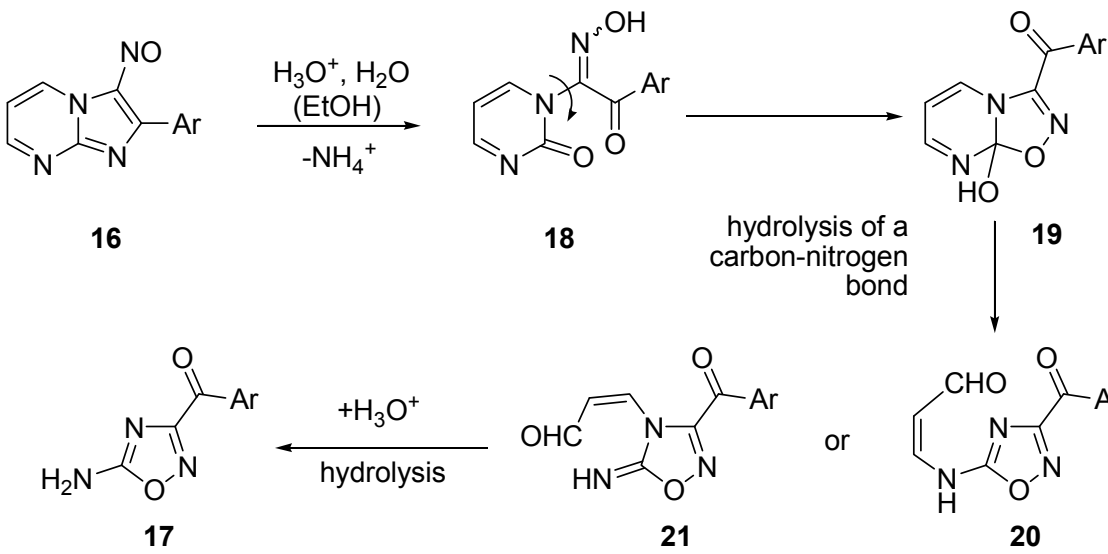

18

hydrolysis of a
carbon-nitrogen

19

$(d)$

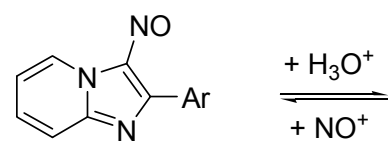

22<smiles>N=c1onc(C(=O)Br)n1/C=C\C=O</smiles><smiles>O=C/C=C\Nc1nc(C(=O)Br)no1</smiles>

20

Overall, experimental data indicated an activity to decrease the heart force (negative inotropic activity) comparable to that of diltiazem [11], but we achieved a compound 24-fold more potent than diltiazem (25 in Figure 1) [12]. The negative inotropic activity was modulated by modifying the structure at the phenyl ring (at C8), at the C5-C6 bond, and by substituting the hydroxyl group with alkoxyl chains [11,12]. Recently, we published three other potent derivatives [26], characterized by the condensed benzothiazino ring and the $\mathrm{CF}_{3} / \mathrm{CH}_{3}$ substitution at the $\mathrm{R}$ chain (26-28 in Figure 1). Here, we propose a further extension of the series of oxadiazolothiazinones to other peculiar molecules. 
Figure 1. Structure of diltiazem (24), of published (compounds 25-29, 38) and novel oxadiazolothiazinone derivatives (compounds 30-37, 39, 40), whose LTCC data is presented below.

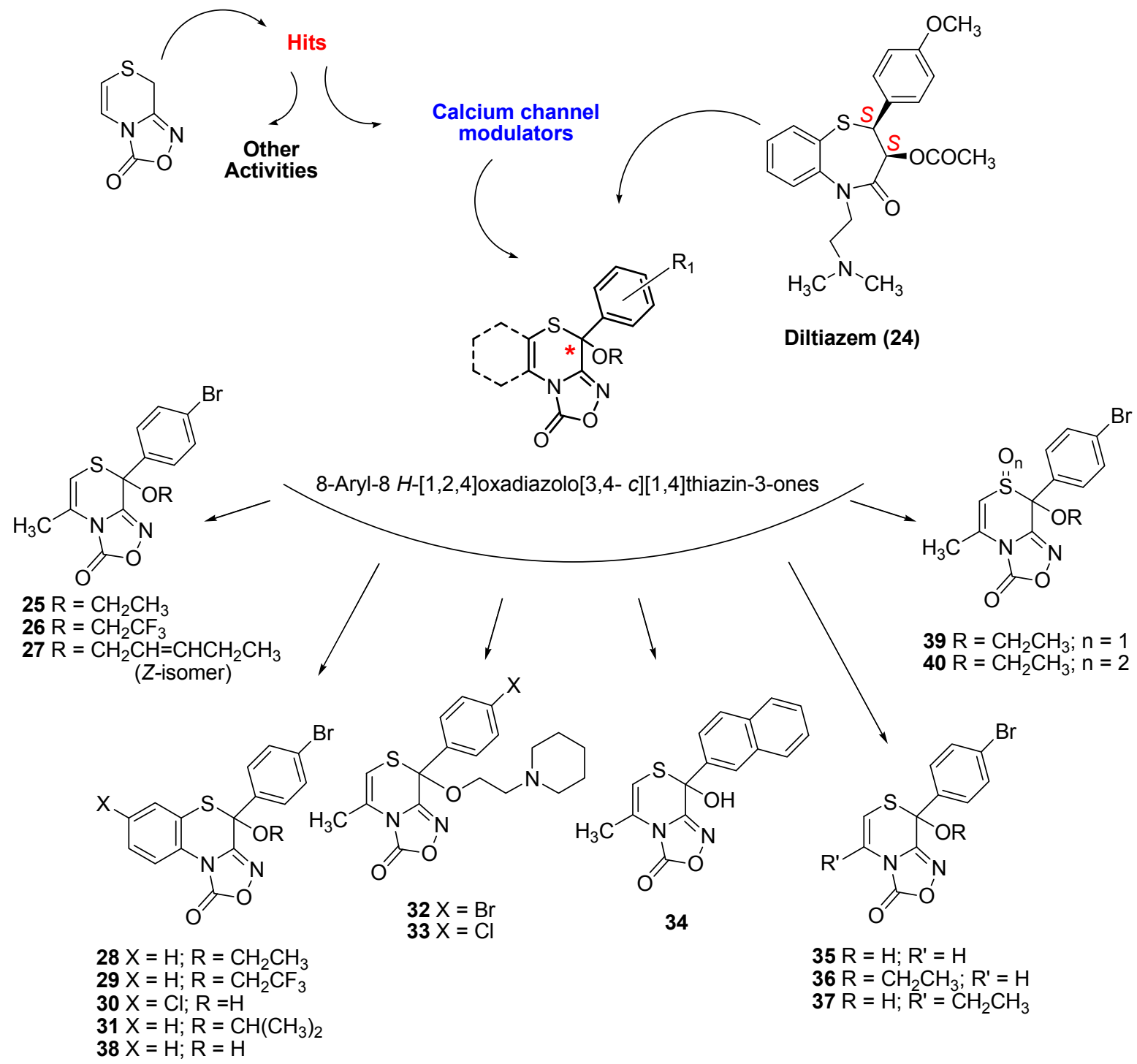

\section{Results and Discussion}

\subsection{Synthesis of Oxadiazolothiazinones}

In vitro data for 11 molecules (Figure 1) and the synthesis of most of them is presented here for the first time: two benzofused derivatives $\mathbf{3 0}$ and 31, two derivatives $\mathbf{3 2}$ and $\mathbf{3 3}$ with a basic group at the alkyloxyl chain, one derivative $\mathbf{3 4}$ with a naphthyl group replacing the phenyl at $\mathrm{C} 8$, and another three (compounds 35-37) with minor changes at the C5-C6 bond. The synthesis of one benzofused derivative $\mathbf{3 8}$ as well as of derivatives $39, \mathbf{4 0}$ with an oxidized sulphur atom of the thiazino moiety, has already been published [26,27].

We obtained the new hemithioacetals 30, 35, and $\mathbf{3 7}$ following the general three-steps procedure of Scheme 3a: first, the treatment of 2-aminothiazoles 41a-c with 2,4'-dibromoacetophenone gives the 4-bromophenylimidazo[2,1-b][1,3]thiazoles $\mathbf{4 2 a}-\mathbf{c}$; these compounds, by reaction with sodium nitrite 
in acetic acid, give the nitroso derivatives $\mathbf{4 3 a}-\mathbf{c}$; which in turn were converted into the corresponding $[1,2,4]$ oxadiazol[3,4-c][1,4]thiazinones by the action of hydrochloric acid. An analogous route gives the new hemithioacetal 34 via compounds $\mathbf{4 2 d}$ and $\mathbf{4 3 d}$ (Scheme 3b).

Scheme 3. Synthetic route for hemithioacetals 30, 35, 37 starting from the opportune thiazole 41a-c (a), synthetic route for hemithioacetal 34 starting from the aminothiazole 41d (b), synthesis of thioketals 31 and $\mathbf{3 6}$ (c) and synthetic route for thioketals $\mathbf{3 2}$ and $\mathbf{3 3}$, via the thioketals 46 and 47 respectively $(\mathbf{d})$.

(a)<smiles>[R]c1nc(N)sc1[R]</smiles>

a $\mathrm{R}-\mathrm{R}^{\prime}=\mathrm{CH}=\mathrm{CH}-\mathrm{CCl}=\mathrm{CH}$

b $\mathrm{R}=\mathrm{H} ; \mathrm{R}^{\prime}=\mathrm{H}$

c $\mathrm{R}=\mathrm{CH}_{3} \mathrm{CH}_{2} ; \mathrm{R}^{\prime}=\mathrm{H}$

(b)<smiles>CC(C)=O</smiles>

(c)<smiles>[R]C1=C([R])n2c(noc2=O)C(O)(c2ccc(Br)cc2)S1</smiles>

$35 \mathrm{R}=\mathrm{H} ; \mathrm{R}^{\prime}=\mathrm{H}$

$38 \mathrm{R}^{-\mathrm{R}^{\prime}}=\mathrm{CH}=\mathrm{CH}-\mathrm{CH}=\mathrm{CH}$

(d)

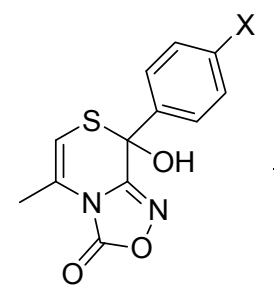

$44 X=\mathrm{Br}$
$45 \mathrm{X}=\mathrm{Cl}$

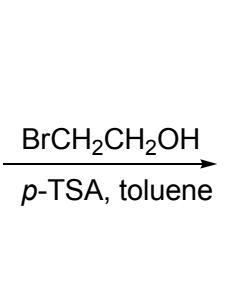

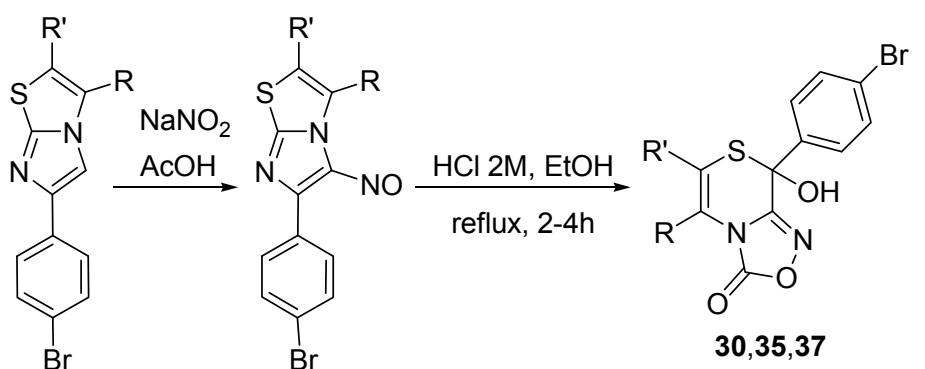

42a-c

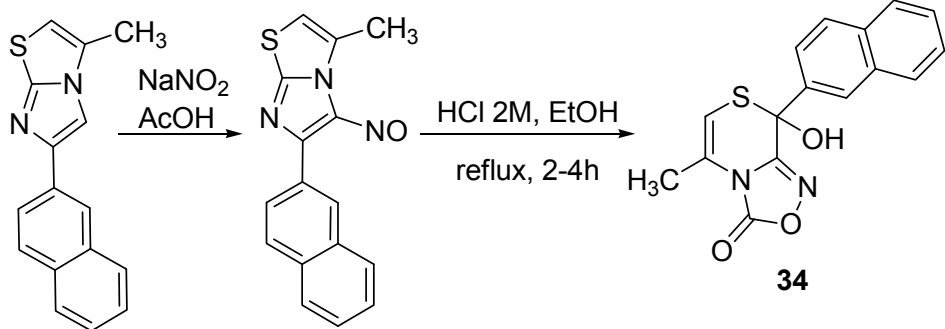

42d

43d

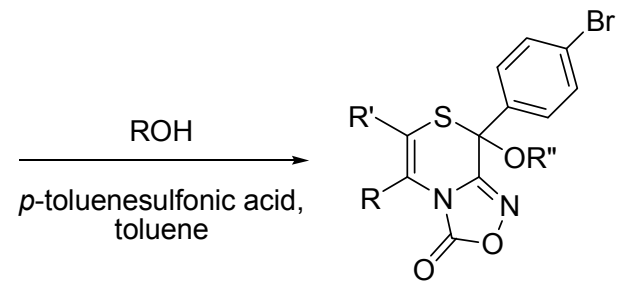

$36 \mathrm{R}=\mathrm{H}, \mathrm{R}^{\prime}=\mathrm{H} ; \mathrm{R}^{\prime \prime}=\mathrm{CH}_{2} \mathrm{CH}_{3}$

$31 \mathrm{R}-\mathrm{R}^{\prime}=\mathrm{CH}=\mathrm{CH}-\mathrm{CH}=\mathrm{CH} ; \mathrm{R}^{\prime \prime}=\mathrm{CH}\left(\mathrm{CH}_{3}\right)_{2}$

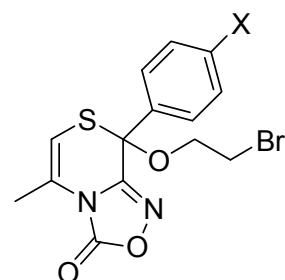

$46 \mathrm{X}=\mathrm{Br}$

$47 \mathrm{X}=\mathrm{Cl}$

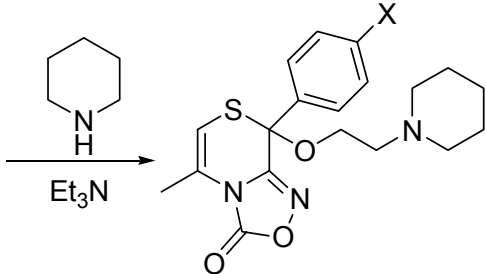

$32 X=\mathrm{Br}$
$33 \times=\mathrm{Cl}$

Reagents and conditions: (i) in the instance of 41a: $\mathrm{EtOH}, \mathrm{Et}_{3} \mathrm{~N}$, reflux; (ii) in the instance of 41b, c: $\mathrm{CH}_{3} \mathrm{COCH}_{3}$, or $\mathrm{CHCl}_{3}$, reflux then $\mathrm{HCl} 2 \mathrm{M}$, EtOH, reflux.

The thioketals 31 and 36 were obtained by reacting 38 or 35 with the appropriate alcohol and refluxing in toluene in the presence of $p$-toluenesulfonic acid as catalyst (Scheme 3c). Two steps 
were necessary for the syntheses of $\mathbf{3 2}$ and 33, obtained by reaction of 44 [19] or 45 [18] with 2-bromoethanol by refluxing in toluene in the presence of $p$-toluenesulfonic acid as catalyst (Scheme $3 \mathrm{~d}$ ) to give the corresponding intermediate $\mathbf{4 6}$ or $\mathbf{4 7}$. These were subsequently reacted with piperidine to give $\mathbf{3 2}$ or $\mathbf{3 3}$.

\subsection{Biological Activity of Oxadiazolothiazinones as L-Type Calcium Channel Blockers}

We assessed the cardiac activity of these oxadiazolothiazinones on guinea-pig left and right atria, as well as their relaxant activity on guinea-pig vascular (aorta) and nonvascular (ileum) smooth muscle. For some of them, with electrophysiology experiments we tested the modulation of the LTCC, whereas with binding experiments we tested diltiazem displacement from its binding site on LTCC.

\subsubsection{Functional Data}

As with the reference compound 25, all of the tested compounds were shown to be negative inotropic agents: half of them are more potent than diltiazem, and two of them are of the same order of potency as 25 (Table 1). Previous findings about the substituted phenyl ring ( $p$-bromine more potent than $p$-chlorine) were confirmed: 35 resulted 32-fold more potent than its chlorine-analogue [11]. Concerning the substitution at $\mathrm{C} 8$ with an $\mathrm{OH} / \mathrm{OR}$ group, compound $\mathbf{3 8}$ is much less potent than its ethoxy derivative 28 [26]. Pairwise comparisons also show that the methyl on the thiazino ring is not essential, but methyl/ethyl replacement is detrimental: $\mathbf{3 6}$ and $\mathbf{2 5}$ have comparable potency, whereas $\mathbf{3 7}$ is about 8 -fold less potent than 35. Relevant information arises from peculiar structural modifications: the effect of sulphur oxidation is detrimental for the potency, with the sulphone $\mathbf{4 0}$ slightly better than sulphoxide 39; instead, the presence of chlorine at the fused benzothiazino ring enhances the potency. For all but two compounds (32 and 33) the negative chronotropic activity is absent. The weak chronotropic activity observed for $\mathbf{3 2}$ and $\mathbf{3 3}$ comes together with the reduction of the inotropic activity. The lack of selectivity observed for $\mathbf{3 2}$ and $\mathbf{3 3}$ is unique among the large series of oxadiazolothiazinone analogues that we have studied so far. In particular, the comparison with the data of the analogue with the $\mathrm{CH}_{2}$-cyclohexyl as lateral chain (compounds 20a, $\mathbf{b}$ of reference [12], that are very selective toward inotropy), let us suppose that because of the piperidine ring the molecule interacts with different calcium channel isoforms, thus causing both weak inotropy and weak chronotropy.

The pharmacological profile of all compounds was extended to relaxant activities (Table 2), by using $80 \mathrm{mM} \mathrm{K} \mathrm{K}^{+}$-depolarized guinea-pig aortic strips and nonvascular ileum longitudinal smooth muscle. The relaxation of nonvascular tissues, and in particular of ileum longitudinal smooth muscle, may cause undesired side effects such as constipation when treating a patient with an LTCC blocker as antihypertensive. In vascular smooth muscle, only two compounds (30 and 34) were active; the uniqueness of $\mathbf{3 4}$ is the naphthyl group in place of the phenyl at $\mathrm{C} 8$, whereas the uniqueness of $\mathbf{3 0}$ is the chlorine substitution at the fused benzothiazino ring, with a certain resemblance to the diltiazem derivative, clentiazem. 
Table 1. Cardiac activity of compounds 24-40.

\begin{tabular}{|c|c|c|c|c|c|c|}
\hline \multirow[b]{3}{*}{ Compd } & \multicolumn{3}{|c|}{ Left Atrium } & \multicolumn{3}{|c|}{ Right Atrium } \\
\hline & \multicolumn{3}{|c|}{ Negative Inotropy } & \multicolumn{3}{|c|}{ Negative Chronotropy } \\
\hline & $\begin{array}{c}\text { Activity }^{a} \\
(M \pm \text { SEM) }\end{array}$ & $\mathrm{EC}_{50}{ }^{b}(\mu \mathrm{M})$ & $\begin{array}{c}95 \% \text { conf lim } \\
\left(\times 10^{-6}\right) \\
\end{array}$ & $\begin{array}{c}\text { Activity }^{c} \\
\left(M \pm \text { SEM}^{2}\right)\end{array}$ & $\mathrm{EC}_{30}{ }^{b}(\mu \mathrm{M})$ & $\begin{array}{c}95 \% \text { conf lim } \\
\left(\times 10^{-6}\right)\end{array}$ \\
\hline 24 & $78 \pm 3.5$ & 0.79 & $0.70-0.85$ & $94 \pm 5.6^{d}$ & 0.07 & $0.064-0.075$ \\
\hline $25^{e}$ & $77 \pm 1.7^{d}$ & 0.04 & $0.03-0.05$ & $5 \pm 0.2^{f}$ & & \\
\hline $26^{g}$ & $76 \pm 2.5^{h}$ & 0.022 & $0.015-0.031$ & $4 \pm 0.1$ & & \\
\hline $27^{e}$ & $81 \pm 2.9^{i}$ & 0.63 & $0.45-0.80$ & $20 \pm 1.1^{i}$ & & \\
\hline $28^{g}$ & $81 \pm 3.9^{d}$ & 0.013 & $0.0085-0.018$ & $7 \pm 0.2^{f}$ & & \\
\hline $29^{g}$ & $75 \pm 1.7^{d}$ & 0.0060 & $0.0042-0.0087$ & $7 \pm 0.3^{f}$ & & \\
\hline 30 & $87 \pm 2.3$ & 0.36 & $0.26-0.48$ & $2 \pm 0.2$ & & \\
\hline 31 & $82 \pm 2.6^{i}$ & 0.44 & $0.32-0.61$ & $2 \pm 0.1^{f}$ & & \\
\hline 32 & $76 \pm 2.7$ & 3.67 & $2.91-4.12$ & $56 \pm 3.1$ & 5.06 & $4.38-5.91$ \\
\hline 33 & $88 \pm 0.4^{i}$ & 5.25 & $3.29-8.36$ & $52 \pm 1.9$ & 6.25 & $5.14-7.36$ \\
\hline 34 & $95 \pm 1.3^{i}$ & 0.057 & $0.040-0.082$ & $7 \pm 0.1$ & & \\
\hline 35 & $88 \pm 3.6$ & 0.13 & $0.090-0.17$ & $28 \pm 1.6^{f}$ & & \\
\hline 36 & $85 \pm 3.2$ & 0.039 & $0.024-0.064$ & $34 \pm 1.4$ & & \\
\hline 37 & $85 \pm 4.2$ & 1.11 & $0.76-1.61$ & $16 \pm 0.7$ & & \\
\hline 38 & $68 \pm 2.3$ & 4.23 & $3.45-5.26$ & $29 \pm 1.6$ & & \\
\hline 39 & $95 \pm 3.6^{f}$ & 1.08 & $0.67-1.93$ & $5 \pm 0.3$ & & \\
\hline 40 & $92 \pm 3.4^{f}$ & 0.76 & $0.52-1.12$ & $16 \pm 0.9$ & & \\
\hline
\end{tabular}

${ }^{a}$ Decrease in developed tension on isolated guinea-pig left atrium at $10^{-5} \mathrm{M}$, expressed as percent changes from the control $(\mathrm{n}=5-6)$. The left atria were driven at $1 \mathrm{~Hz}$. The $10^{-5} \mathrm{M}$ concentration gave the maximum effect for most compounds; ${ }^{b}$ Calculated from log concentration-response curves (Probit analysis by Litchfield and Wilcoxon [28] with $\mathrm{n}=6-7$ ). When the maximum effect was $<50 \%$, the $\mathrm{EC}_{50}$ ino., $\mathrm{EC}_{30}$ chrono., values were not calculated; ${ }^{c}$ Decrease in atrial rate on guinea-pig spontaneously beating isolated right atrium at $10^{-5} \mathrm{M}$, expressed as percent changes from the control $(\mathrm{n}=7-8)$. The $10^{-5} \mathrm{M}$ concentration gave the maximum effect for most compounds. Pretreatment heart rate ranged from 165 to 190 beats $/ \mathrm{min}$; ${ }^{d}$ At the $10^{-6} \mathrm{M}$; ${ }^{e}$ From reference $12 ;{ }^{f}$ At the $10^{-4} \mathrm{M}$; ${ }^{g}$ From reference $26{ }^{h}$ At the $5 \times 10^{-6} \mathrm{M}$; ${ }^{i}$ At the $5 \times 10^{-5}$ M. $95 \%$ conf lim stands for $95 \%$ confidence limit.

Table 2. Relaxant activity of compounds $\mathbf{2 4 - 4 0}$ on $\mathrm{K}^{+}$-depolarized guinea pig vascular and nonvascular smooth muscle.

\begin{tabular}{|c|c|c|c|c|c|c|}
\hline \multirow[b]{2}{*}{ Compd } & \multicolumn{3}{|c|}{ Aorta } & \multicolumn{3}{|c|}{ Ileum } \\
\hline & $\begin{array}{c}\text { Activity }^{a} \\
(\mathbf{M} \pm \text { SEM })\end{array}$ & $\mathrm{IC}_{50}^{b}(\mu \mathrm{M})$ & $\begin{array}{c}95 \% \text { conf } \lim \\
\left(\times 10^{-6}\right)\end{array}$ & $\begin{array}{c}\text { Activity }^{a} \\
(\mathbf{M} \pm \text { SEM) }\end{array}$ & $\mathrm{IC}_{50}{ }^{b}(\mu \mathrm{M})$ & $\begin{array}{c}95 \% \text { conf lim } \\
\left(\times 10^{-6}\right)\end{array}$ \\
\hline 24 & $88 \pm 2.3$ & 2.6 & $2.2-3.1$ & $98 \pm 1.5^{c}$ & 0.11 & $0.085-0.13$ \\
\hline $25^{d}$ & $19 \pm 0.9^{e}$ & & & $3 \pm 0.2$ & & \\
\hline $26^{f}$ & $28 \pm 1.7$ & & & $73 \pm 0.2$ & 25.94 & $18.97-35.45$ \\
\hline $27^{d}$ & $11 \pm 0.8^{e}$ & & & $*$ & & \\
\hline $28^{f}$ & $4 \pm 0.3$ & & & $87 \pm 1.5$ & 8.32 & $6.37-10.85$ \\
\hline $29^{f}$ & $21 \pm 0.9$ & & & $54 \pm 2.1$ & 11.79 & $4.33-18.21$ \\
\hline 30 & $57 \pm 3.3$ & 25.82 & $13.54-49.24$ & $90 \pm 1.6^{e}$ & 19.73 & $8.25-23.12$ \\
\hline 31 & $10 \pm 0.9$ & & & $58 \pm 1.4$ & 13.99 & $10.67-18.34$ \\
\hline 32 & $43 \pm 2.3$ & & & $85 \pm 1.6^{g}$ & 3.26 & $2.58-4.11$ \\
\hline
\end{tabular}


Table 2. Cont.

\begin{tabular}{|c|c|c|c|c|c|c|}
\hline \multirow[b]{2}{*}{ Compd } & \multicolumn{3}{|c|}{ Aorta } & \multicolumn{3}{|c|}{ Ileum } \\
\hline & $\begin{array}{c}\text { Activity }^{a} \\
(\mathbf{M} \pm \text { SEM) }\end{array}$ & $\mathrm{IC}_{50}{ }^{b}(\mu \mathrm{M})$ & $\begin{array}{c}95 \% \text { conf lim } \\
\left(\times 10^{-6}\right)\end{array}$ & $\begin{array}{c}\text { Activity }^{a} \\
(\mathbf{M} \pm \text { SEM) }\end{array}$ & $\mathrm{IC}_{50}{ }^{b}(\mu \mathrm{M})$ & $\begin{array}{c}95 \% \text { conf lim } \\
\left(\times 10^{-6}\right)\end{array}$ \\
\hline 33 & $31 \pm 2.9$ & & & $64 \pm 2.4^{g}$ & 5.51 & $4.36-6.96$ \\
\hline 34 & $70 \pm 2.9$ & 29.88 & $18.35-31.07$ & $98 \pm 1.0$ & 13.22 & $10.67-16.38$ \\
\hline 35 & $26 \pm 2.5$ & & & $66 \pm 2.4$ & 34.36 & $27.72-42.59$ \\
\hline 36 & $27 \pm 1.6$ & & & $86 \pm 1.7$ & 16.63 & $13.63-20.27$ \\
\hline 37 & $45 \pm 0.7$ & & & $59 \pm 0.1^{g}$ & 7.87 & $6.73-9.20$ \\
\hline 38 & $31 \pm 0.7$ & & & $78 \pm 2.4^{g}$ & 3.49 & $2.77-4.42$ \\
\hline 39 & $22 \pm 2.1$ & & & $91 \pm 3.4$ & 21.35 & $17.26-26.40$ \\
\hline 40 & $19 \pm 0.9$ & & & $52 \pm 0.3^{g}$ & 9.97 & $8.39-10.85$ \\
\hline
\end{tabular}

${ }^{a}$ Percent inhibition of calcium-induced contraction on $\mathrm{K}+$-depolarized $(80 \mathrm{mM})$ guinea pig aortic strips and longitudinal smooth muscle (at $10^{-4} \mathrm{M}$ ). The $10^{-4} \mathrm{M}$ concentration gave the maximum effect for most compounds respectively; ${ }^{b}$ Calculated from log concentration- response curves (Probit analysis by Litchfield and Wilcoxon [28] with $\mathrm{n}=6-7$ ). When the maximum effect was $<50 \%$, the $\mathrm{IC}_{50}$ values were not calculated; ${ }^{c}$ At the $10^{-6} \mathrm{M} ;{ }^{d}$ From reference $12 ;{ }^{e}$ At the $5 \times 10^{-5} \mathrm{M} ;{ }^{f}$ From reference $26 ;{ }^{g}$ At the $10^{-5} \mathrm{M} ;{ }^{*}$ Not tested. $95 \%$ conf lim stands for $95 \%$ confidence limit.

In nonvascular smooth muscle, all of the tested molecules (with $\mathbf{2 5}$ as the only exception) show activity in the ileum, but diltiazem remains more potent than all of them. With these experimental conditions any relaxant activity of nonvascular smooth muscle, if present, would be attributed to a calcium antagonist activity.

\subsubsection{Electrophysiology and Binding Data}

It is well established that contraction of smooth muscle is initiated, and to a lesser extent maintained, by a rise in the concentration of free $\mathrm{Ca}^{2+}$ in the cell cytoplasm [29]. This activator $\mathrm{Ca}^{2+}$ can either enter from the extracellular space through a variety of $\mathrm{Ca}^{2+}$ permeable ion channels - the best-characterized $\mathrm{Ca}^{2+}$ entry pathway utilizes LTCC-or be released by the sarcoplasmic reticulum [30-32].

Although all of the molecules contain the same scaffold, only two of them exhibit a vasorelaxant effect (compounds 30 and 34) and only two exhibit a chronotropic effect (compounds 32 and 33). Thus, we selected $\mathbf{3 0}$ and $\mathbf{3 2}$ for in-depth studies. The effects of compounds $\mathbf{3 0}$ and $\mathbf{3 2}$ on vascular smooth muscle have been presently investigated under experimental conditions that allow for the identification of blockers of these LTCC. At first, we tested compounds $\mathbf{3 0}$ and $\mathbf{3 2}$ on single smooth muscle cells isolated from the rat tail main artery, in order to provide direct evidence of their LTCC blocking activity.

Compound 32 inhibited $\mathrm{I}_{\mathrm{Ba}(\mathrm{L})}\left(\mathrm{Ba}^{2+}\right.$ current through L-type $\mathrm{Ca}^{2+}$ channels), measured at $0 \mathrm{mV}$ from a holding potential $(\mathrm{Vh})$ of $-80 \mathrm{mV}$, in a concentration-dependent manner (Figure 2a) with an estimated $\mathrm{IC}_{50}$ of $30 \mu \mathrm{M}$ and accelerated its inactivation kinetics (data not shown). On the contrary, IBa recorded at $-40 \mathrm{mV}$ from $\mathrm{V}_{\mathrm{h}}$ of $-80 \mathrm{mV}$ (an indicator of T-type currents $\left[\mathrm{I}_{\mathrm{Ba}(\mathrm{T})}\left(\mathrm{Ba}^{2+}\right.\right.$ current through T-type $\mathrm{Ca}^{2+}$ channels)]) was not significantly modified by 32 up to a concentration of $30 \mu \mathrm{M}$. The current-voltage relationship (Figure $2 \mathrm{~b}$ ) shows that $\mathbf{3 2}$ significantly decreased the peak inward current 
in the range between $-30 \mathrm{mV}$ and $50 \mathrm{mV}$ without varying the apparent maximum at about $10 \mathrm{mV}$ and the threshold at about $-30 \mathrm{mV}$.

Figure 2. Effect of compound 32 on $\mathrm{I}_{\mathrm{Ba}}$ in single tail artery myocytes. (a) Concentration-dependent effect of $\mathbf{3 2}$ at the peak of $\mathrm{I}_{\mathrm{Ba}(\mathrm{L})}$ and $\mathrm{I}_{\mathrm{Ba}(\mathrm{T})}$ trace. On the ordinate scale, response is reported as percentage of control. Data points are mean \pm SEM ( $\mathrm{n}=3-6$ ); (b) Current-voltage relationships, recorded from a $\mathrm{Vh}$ of $-80 \mathrm{mV}$, constructed prior to the addition (control) and in the presence of $30 \mu \mathrm{M}$ 32. Data points are mean \pm SEM $(\mathrm{n}=6) . * p<0.05, * * p<0.01, * * * p<0.001 v s$. control, Student's $t$ test for paired samples.

(a)

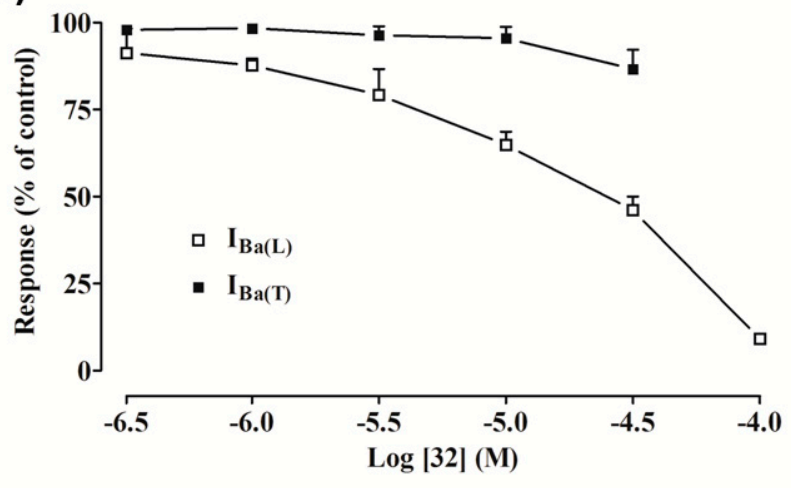

(b)

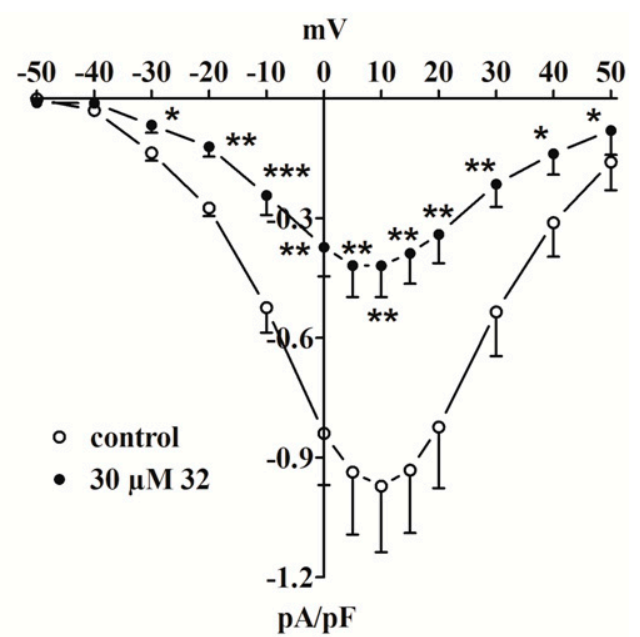

Similar results were obtained with 30, which was ineffective on $\mathrm{IBa}_{\mathrm{Ba}} \mathrm{T}$ (data not shown), decreased $\mathrm{IBa}(\mathrm{L})$ by about $50 \%$ at $3 \mu \mathrm{M}$ (Figure $3 \mathrm{a}$ ), accelerated its decay (data not shown), and reduced the current-voltage relationship in the range between $-30 \mathrm{mV}$ and $40 \mathrm{mV}$ (Figure 3b). Noticeably, a strong outward current (possibly ascribable to $\mathrm{Cs}^{+}$flowing through LTCC) appeared when myocytes were challenged with $10 \mu \mathrm{M} 30$.

High $\mathrm{K}^{+}$-induced contraction of aorta strips is the result of an increased $\mathrm{Ca}^{2+}$ influx through LTCCs and is specifically inhibited by $\mathrm{Ca}^{2+}$-antagonists. We found that compounds $\mathbf{3 0}$ and $\mathbf{3 2}$ antagonize high $\mathrm{K}^{+}$-induced contraction in a concentration-dependent manner. Therefore, this inhibition might be interpreted as a consequence of the blockade of LTCC. The electrophysiological data presented here directly confirm this hypothesis, since both compounds inhibited $\mathrm{I}_{\mathrm{Ba}(\mathrm{L})}$ in rat tail artery myocytes; their potency, however, was one order of magnitude lower than that exhibited in inhibiting high $\mathrm{K}^{+}$-induced contractions. This observation suggests that the vasorelaxing activity, lower as one should expect from the LTCC-blocking effect, is likely limited either by the diffusion of the drugs into the whole tissue or by the $t_{0.5}$ of the agents. Furthermore, slight differences in L-type $\mathrm{Ca}^{2+}$ channels expressed in the two tissues examined might explain the incomplete matching of data from the two experimental settings.

Compounds 30- and 32-induced inhibition of $\mathrm{I}_{\mathrm{Ba}(\mathrm{L})}$, observed at $0.067 \mathrm{~Hz}$, a frequency that allows full recovery between pulses from $\mathrm{Ca}_{\mathrm{v}} 1.2$ channel inactivation in rat tail artery myocytes [33], was tonic in nature and developed independently of channel activation [32]. This is interpreted as a consequence of the selective inhibition of the resting channel. In addition, the faster LTCC inactivation kinetics observed in the presence of both compounds (data not shown), reported also for other LTCC 
blockers such as dihydropyridines and phenylalkylamines [34], likely indicates that the drugs exert an open channel inhibition [35].

Figure 3. Effect of compound $\mathbf{3 0}$ on $\mathrm{IBa}_{\mathrm{B}(\mathrm{L})}$ in single tail artery myocytes. (a) Concentration-dependent effect of $\mathbf{3 0}$ at the peak of $\mathrm{I}_{\mathrm{Ba}(\mathrm{L})}$ trace. On the ordinate scale, response is reported as percentage of control. Data points are mean \pm SEM $(n=4-5)$; (b) Current-voltage relationships, recorded from a $\mathrm{Vh}_{\mathrm{h}}$ of $-80 \mathrm{mV}$, constructed prior to the addition (control) and in the presence of $3 \mu \mathrm{M}$ 30. Data points are mean $\pm \operatorname{SEM}(n=5)$. $* p<0.05 v s$. control, Student's $t$ test for paired samples.

(a)

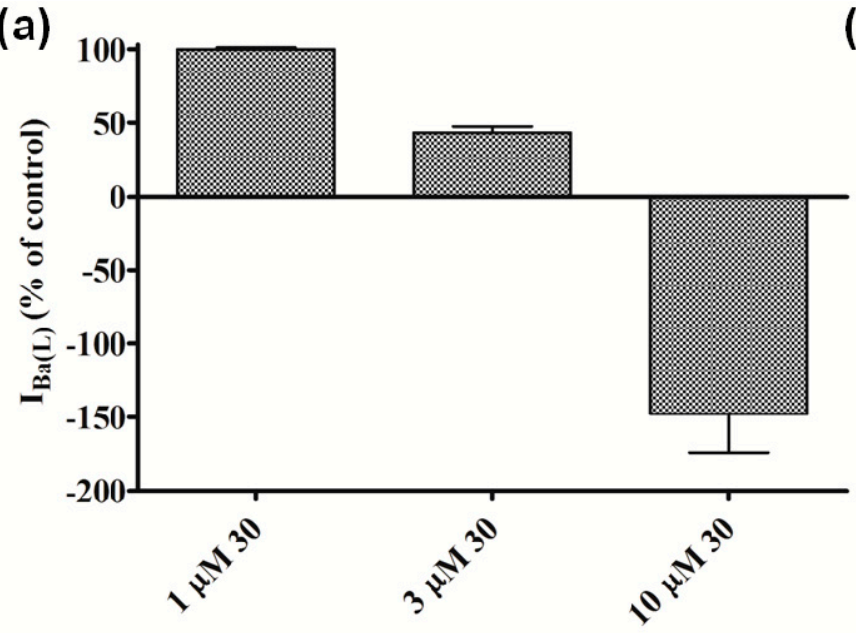

(b)

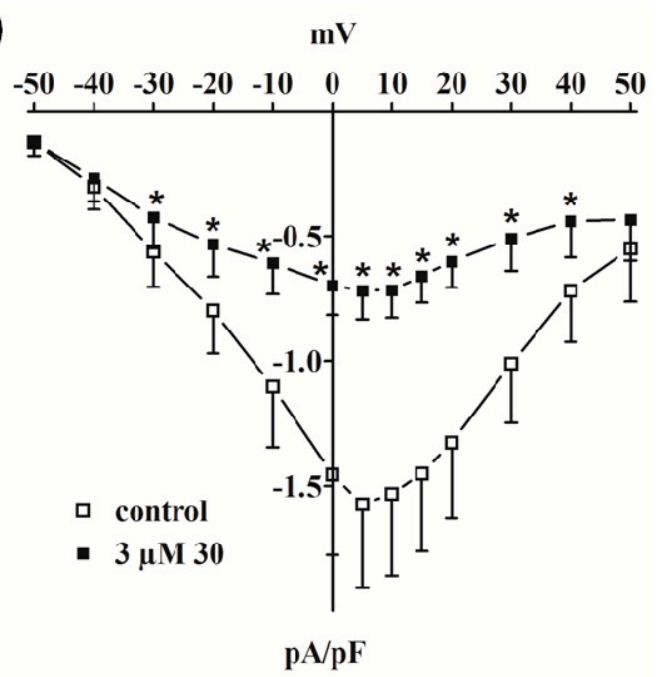

Binding assays on rat cardiomyocytes were carried out in order to establish whether they could displace $\left[{ }^{3} \mathrm{H}\right]$ diltiazem from its binding site. Surprisingly, $32(1 \mathrm{nM}-100 \mu \mathrm{M})$ did not affect $\left[{ }^{3} \mathrm{H}\right]$ diltiazem binding and this along with its low vasorelaxant activity (compared to diltiazem) was considered a sufficient reason for not further investigating the mechanisms underlying 30-mediated chronotropic activity. Compound $\mathbf{3 0}$ even revealed a peculiar behavior which was comparable in part to that observed for its analogue $\mathbf{2 5}$. The latter compound, in fact, displayed a complex interaction with the benzothiazepine receptor since it either stimulated or inhibited the binding of the labeled calcium antagonist at low $(0.1 \mathrm{nM}-1 \mu \mathrm{M})$ or high $(10-100 \mu \mathrm{M})$ concentrations, respectively [36]. Compound 30 was able to potentiate $\left[{ }^{3} \mathrm{H}\right]$ diltiazem binding in a wide range of concentrations $(1 \mathrm{nM}-1 \mu \mathrm{M})$ while it was inactive in the range $1-100 \mu \mathrm{M}$.

\subsection{D-QSAR Model for the LTCC Negative Inotropic Activity of the Oxadiazolothiazinones}

Quantitative structure-activity relationship (QSAR) models relate a set of X-variables to the potency of the response variable, Y; 3D-QSAR methods require three-dimensional molecular structures and use as X-variables various descriptors quantifying electronic, geometric, or steric properties, all calculated over aligned 3D-structures. In the GRID/Golpe 3D-QSAR approach, energy values of the GRID molecular interaction fields (MIF) are used as descriptors [37]. It is well-established that one of the major drawbacks of 3D-QSAR modeling was to define the molecular alignment, especially for compounds with different scaffolds. Some years ago some of us developed a QSAR model for LTCC negative inotropic activity, based on several oxadiazolothiazinones and a few benzothiazepine-like 
compounds; we applied the method named GRIND, that does not directly use the MIF but encodes the energy information into alignment-independent descriptors [12].

From a dynamic perspective, in silico models, including QSAR models, may be updated as soon as new biological data and/or new in silico techniques become available. Recently, we decided to build a new 3D-QSAR model - to be used in the series optimization - solely based on oxadiazolothiazinones and the GRID/3D-QSAR approach. We have enlarged the diversity of the oxadiazolothiazinones and achieved novel potent compounds; in addition, the GRID/3D-QSAR modeling has been revitalized by software that automatically aligns several molecules, even those which are structurally diverse [38].

We assembled a training set of 29 oxadiazolothiazinones, all tested with the exact same experimental conditions. About half of them have the hydroxyl group at $\mathrm{C} 8$, while the others an OR group, with $\mathrm{R}$ being either a short alkyl chain or $\mathrm{CH}_{2} \mathrm{C}_{6} \mathrm{H}_{11}$. Eight molecules of the set are from [11], seven molecules from [12], three molecules from [26], and 11 molecules are new (Figure 1). Data and structures are reported as Supplementary Materials.

These 29 molecules were subjected to 3D-QSAR modeling with the software FLAP [39,40], as described in the Experimental section. The aligned structures are reported in Figure 4a. Once superimposed, values of the GRID MIF compose the X-matrix of the QSAR model: the interaction with the GRID probe $\mathrm{H}$ describes the molecular shape, while the probes DRY and N1 mimic the hydrophobic and H-bonding interactions (in which the ligand atoms act as H-bonding acceptors and protein atoms as donors), respectively.

Figure 4. The three steps of $3 \mathrm{D}-\mathrm{QSAR}$ model: (a) alignment of the structures; (b) graphical analysis of the IVPLS model; (c) inspection of the MIF/pseudofields together with the 3D-structure of the active molecules in order to understand the key regions for the activity. Pseudofields colours of section (c): hydrophobic = green; halogen $=$ grey; aromatic $=$ cyan; H-bond acceptor $=$ red.
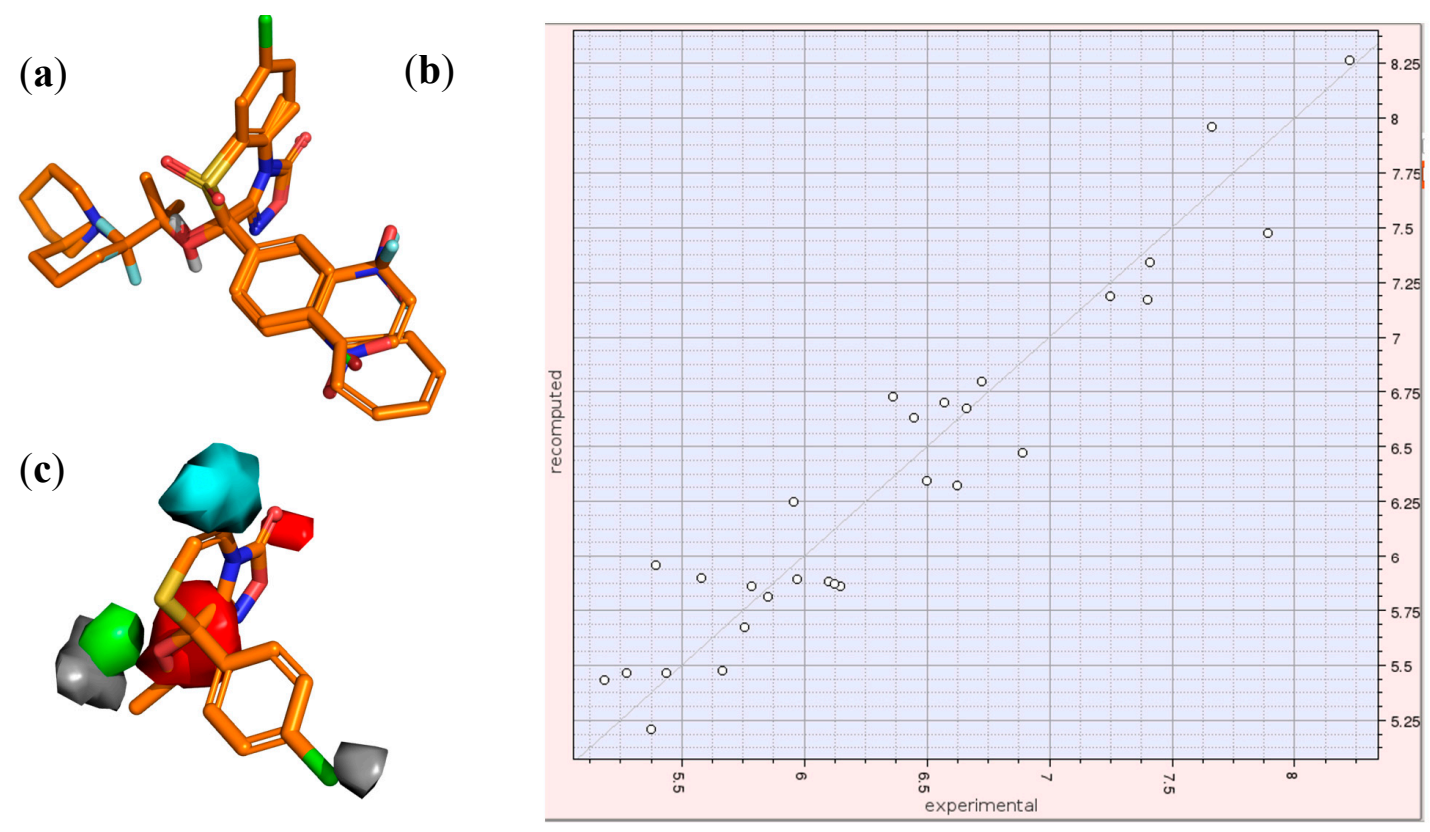

The X-matrix includes also pseudofields, that are a sort of MIF-projection onto the molecular structure. For the dependent variable for the negative inotropic activity, we used the $\mathrm{pEC}_{50}$ of the 
potency, expressed as molar concentration. To align molecules, we used a method based on molecular graphs. Finally, as regression method we used the IVPLS, that stands for Iterative Variable Simplification Partial Least Squares. This multivariate statistical method is able to improve the predictive ability of the regression models with a dimension-wide variable simplification [41].

We obtained a model composed of one latent variable, characterized by excellent correlation coefficients for objects recalculation $\left(\mathrm{R}^{2}=0.91\right)$. Since all the compounds with very high or very low potency values were part of the training set, we considered misleading an external validation based only on compounds with mid-value potency. So, we carried out an internal validation, with the leave-one-out method, that gave a good objects prediction $\left(\mathrm{Q}^{2}=0.56\right)$.

The plot recomputed $v s$ experimental is reported in Figure $4 \mathrm{~b}$. In the mentioned IVPLS model, the variables with the highest impact on the activity are those corresponding to the largest coefficients. The coefficients of these variables can be plotted as isocontour surfaces as in Figure 4c, where we report the pseudofields of the 3D-QSAR model. Key regions are: an aromatic region (cyan), corresponding to the benzofused ring at C5-C6; a hydrophobic region (green) corresponding to the OR alkyl chain; two halogen regions (grey) corresponding to the para-position of the phenyl at the C8 and to the alkyl chain; and two H-bonding accepting regions (red), one corresponding to the nitrogen and $\mathrm{OH} / \mathrm{OR}$ group, and the other to the two oxygen atoms of the oxadiazol-3-one moiety.

In the past, we used the $R$-form of $\mathbf{2 5}$ as a template for ligand-based virtual screening [36], that allowed us to identify new chemotypes active as LTCC blockers. Here, we report how the most potent compounds that resulted from that screening were used together with diltiazem and the most potent oxadiazolothiazinones to build a pharmacophore model valid for small-molecules with LTCC negative inotropic activity (Figure 5).

Figure 5. Pharmacophore model obtained with seven molecules: diltiazem (24), three oxadiazolothiazinones $(\mathbf{2 5}, \mathbf{2 8}$, and 29), and three compounds from [36] (48, 49, and 50). Pseudofield colours: hydrophobic $=$ yellow; H-bond acceptor $=$ red.

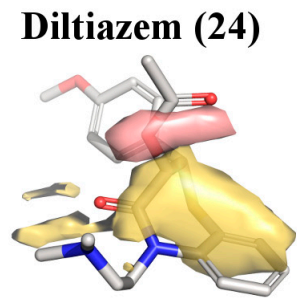

48

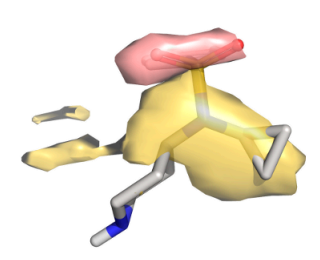

25

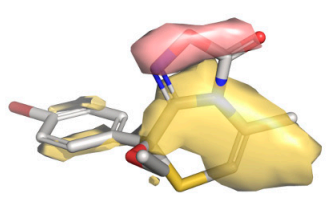

49

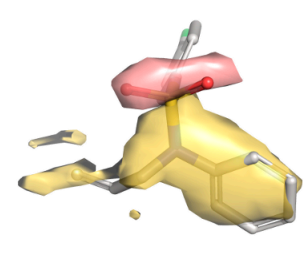

28

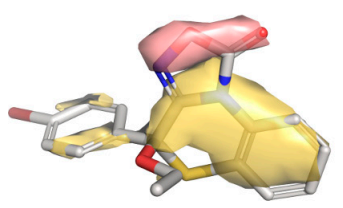

50

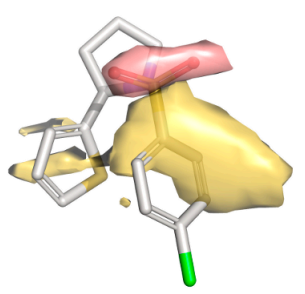

29

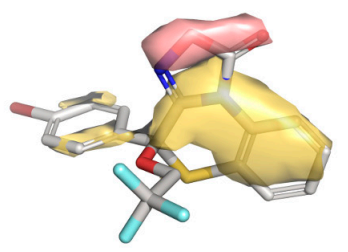

Pharmacophore

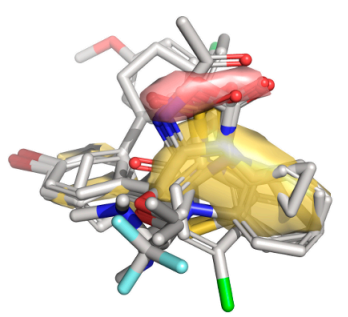

With the FLAPpharm module of FLAP [42] we aligned all of the mentioned structures: the alignment of the pharmacophoric points is maximized through a scoring function that is a weighted 
sum of the shape, hydrophobic and hydrogen-bond MIF similarities. For the aligned molecules we can visualize the pseudofields (Figure 5: hydrophobic $=$ yellow; H-bond acceptor $=$ red), but also the common location of the pharmacophoric points, encoded into a pseudomolecule that can be used as a ligand in a docking procedure (Figure 6), to rationalize structure-activity relationships and study the interaction with the protein (as described below), or as a template in a ligand-based virtual screening (that is beyond the scope of the present paper).

Figure 6. (a,b): Two views of the 3D-structure of LTCC (homology model by Tikonov and Zhorov [43]), in which one calcium ion is shown as a cyan sphere, whereas green and red surfaces represent GRID molecular interaction fields obtained within the pocket with the hydrophobic probe (DRY, field shown at $-2.0 \mathrm{kcal} / \mathrm{mol}$ ) and the carbonyl oxygen probe $(\mathrm{O}$, field shown at $-5.0 \mathrm{kcal} / \mathrm{mol})$, respectively; (c) The pharmacophore, represented by yellow spheres (hydrophobic atoms) and red spheres (H-bonding accepting atoms), is reported docked within the LTCC cavity.

(a)

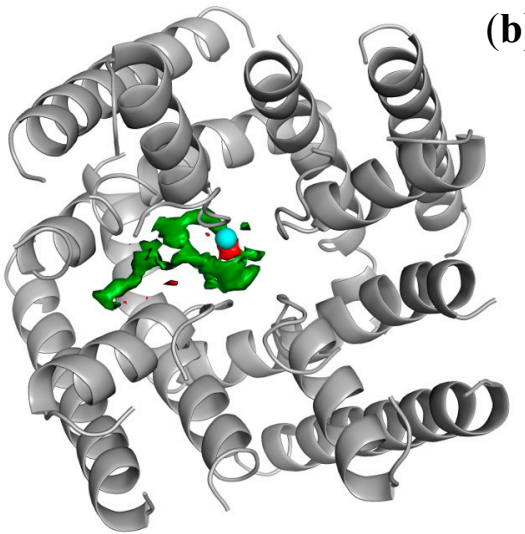

(b)

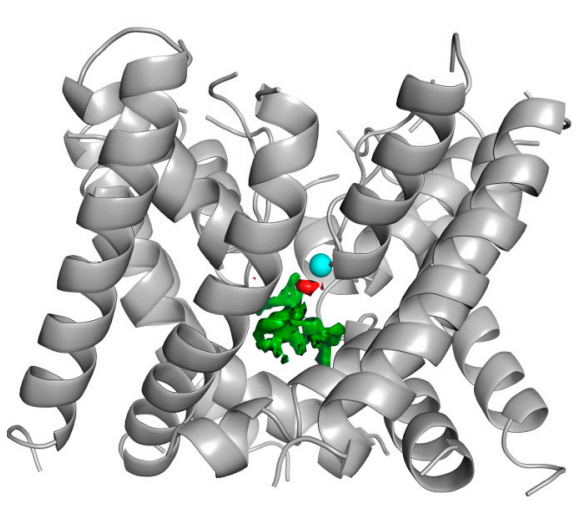

(c)

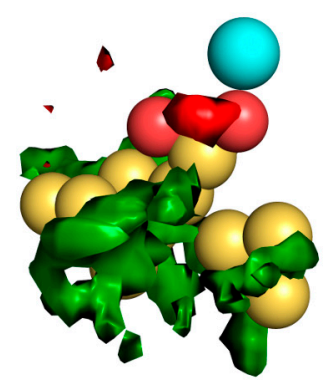

We used a homology model [43] of the LTCC protein as a target for structure-based docking of this pseudomolecule. Figure $6 \mathrm{a}, \mathrm{b}$ show two different views of the pseudomolecule once docked into the LTCC pocket; in Figure 6c the pharmacophore is shown with the sphere-representation in order to highlight the interaction with the calcium ion: yellow spheres represent hydrophobic atoms, whereas the two red spheres the H-bonding accepting atoms. In the interaction with the protein (shown in grey), hydrophobic features interact in correspondence to the green MIF of the protein, whereas a pair of H-bonding accepting atoms, a few Angstroms apart from each other, are likely able to act as chelating agents for the proximal calcium ion (cyan sphere).

Our findings are in agreement with the results from Tikonov and Zhorov [43], who published the homology model for LTCC that we used here, and reported about a ternary complex between diltiazem, the calcium ion, and the protein. The comparison of the docked pharmacophore with diltiazem as within the LTCC protein as proposed by Tikonov and Zhorov is reported as Supplementary Material. The results of the pharmacophore-docking let us hypothesize the formation of a similar ternary complex between each ligand, the calcium ion, and the protein.

In both the 3D-QSAR model (Figure 4) and the pharmacophore-docking (Figures 5 and 6) the oxadiazolone moiety played a major role, with the oxygen atoms key for the interaction with the positively charged calcium ion. In the next section we provide further evidence of the relevance of this 
scaffold in biological interactions: the docking analysis of a set of oxadiazolothiazinones into P-glycoprotein 1.

\subsection{Docking of Oxadiazolothiazinones into Human P-glycoprotein 1 Homology Model}

To study the binding modes of some oxadiazolothiazinones 25-27 to human Pgp-170, we adopted a model of the Nucleotide binding domain 1 (MONBD1), as described in [14]. We obtained a good agreement between in silico predictions (docked solutions of compounds) and in vitro results (MDR1-resistant ovarian A2780/DX3 cancer cells).

The reversal of multidrug resistance was studied in multidrug resistant A2780/DX3 cells. The MTT assay was used to define the activity of doxorubicin with or without the modulators. In our experimental conditions, 27 caused a 76\% increase accumulation of doxorubicin, compared to doxorubicin alone, with values of $0.60 \pm 0.19 \mu \mathrm{M} v s .2 .10 \pm 0.42 \mu \mathrm{M}$. The other two compounds, 25 and 26, did not cause a pharmacologically significant increase of doxorubicin activity (IC50 reduction: 25 : $-20 \%$; 26: $-14 \%$ ). In agreement with experimental in vitro data, we observed significant differences in the docking results, with favorable clusterization and a good score for 27 and unfavorable clusterization observed for $\mathbf{2 5}$ and $\mathbf{2 6}$.

Figure 7. 3D-structure of compound 27 bound to the Nucleotide Binding Domain1 (NBD1) of human $\mathrm{ABCB} 1$, as resulting from docking simulations.

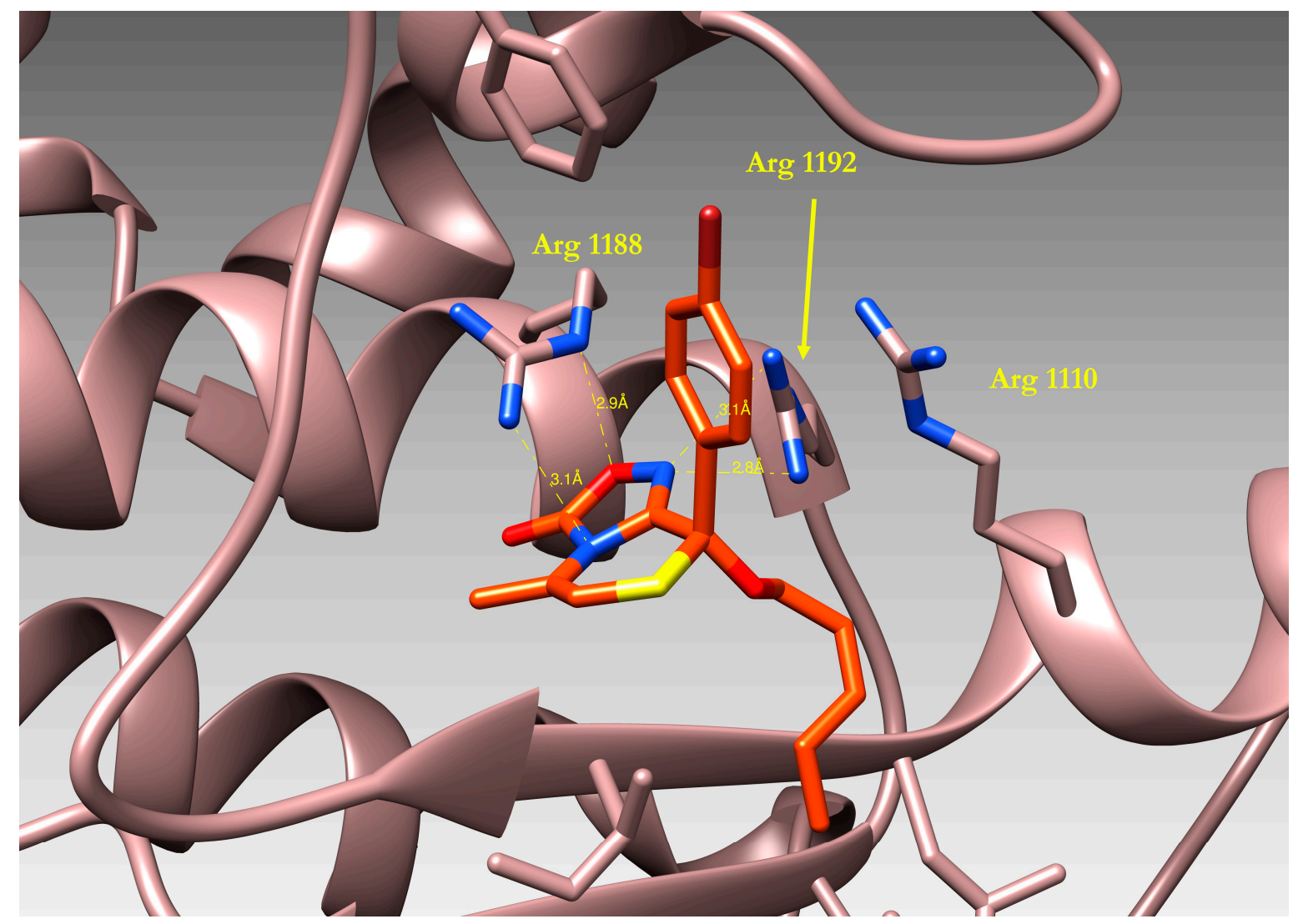

The binding mode of compound $\mathbf{2 7}$ is reported in Figure 7: a visual inspection of the complex formed by the ligand and the protein model evidenced the importance of the oxadiazolothiazinone moiety which is involved in different interactions with the protein binding site. Hydrogen bonds are 
formed with the guanidyl groups of Arginines 1110, 1188 and 1192, and with the OH atom of Ala 1185. On the whole, our data in vitro data confirmed [13] that some of the oxadiazolothiazinones supposed to inhibit the human Pgp-170 were able to potentiate doxorubicin activity in A2780/DX3 resistant cells and, furthermore, were active at concentrations unable to inhibit cell proliferation. Moreover, they were not able to down-regulate the membrane MDR1 thus further suggesting a mechanism of action directly involving the inhibition of the MDR1 transporter.

We calculated the Molecular Electrostatic Potential (MEP) for the protein and for one of the oxadiazolothiazinones (compound 27), represented in Figure 8. The presence of arginines in the binding pocket of P-glycoprotein determines a positively charged environment (blue region in Figure 8a) where the oxadiazolone moiety of $\mathbf{2 7}$ (red fields in Figure 8b) is likely to interact.

Figure 8. (a) Representation of Molecular Electrostatic Potential for the P-glycoprotein and (b) compound 27. In both cases the surface is colored according to its electrostatic potential (blue = positively charged, red = negatively charged). Figure is drawn using the program Chimera [44], electrostatic potential is calculated using the AMBER force field [45].

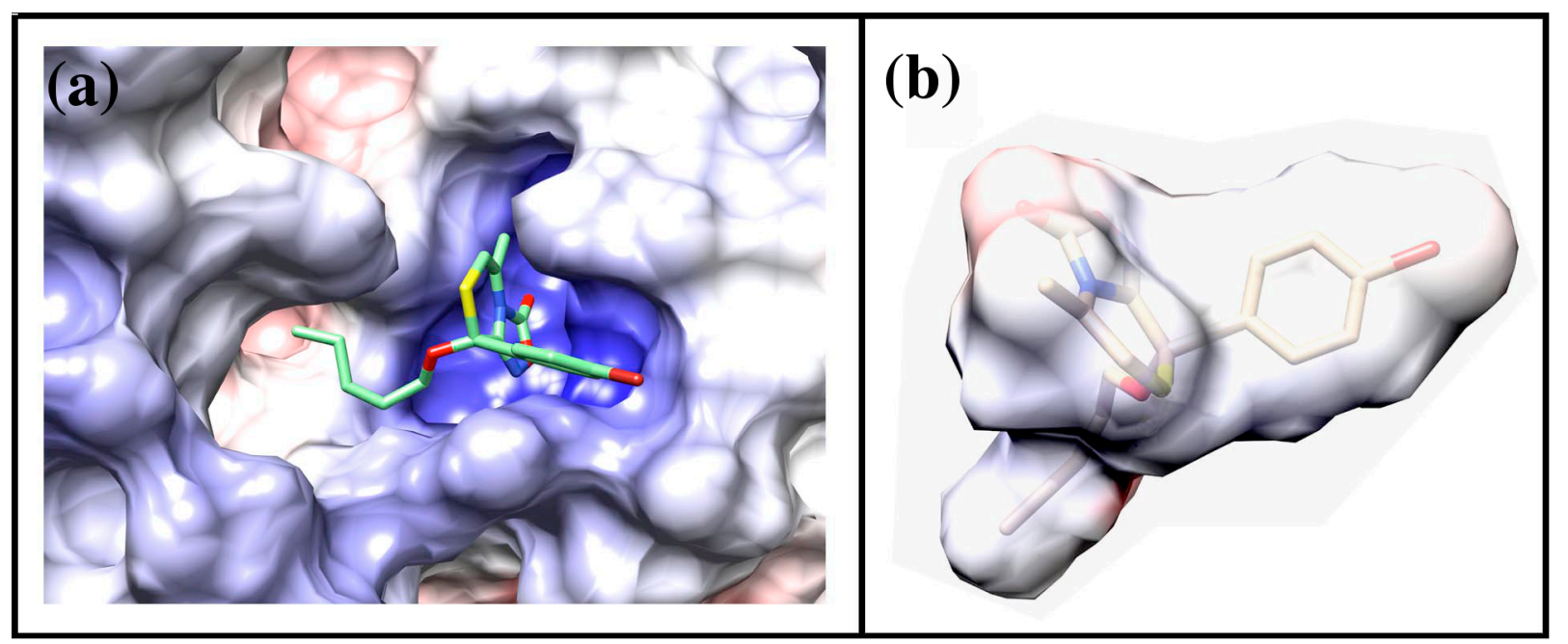

\section{Experimental}

\subsection{General Information}

Compounds 38 [26], 41b [46], 44 [19], and 45 [18], were synthesized according to the respective literature procedures. Compounds $41 \mathbf{a}, \mathbf{c}$, and $\mathbf{d}$ were commercially available. Melting points were determined using a Büchi apparatus B 540 and are uncorrected. ${ }^{1} \mathrm{H}$ - and ${ }^{13} \mathrm{C}-\mathrm{NMR}$ spectra were recorded on a Varian Gemini 300 Instrument in the Fourier transform mode at $25\left( \pm 0.5^{\circ} \mathrm{C}\right)$ in DMSO- $d 6$. Chemical shifts $(\delta)$ are in parts per million (ppm) from tetramethylsilane and coupling constants are in Hertz. ${ }^{1} \mathrm{H}-\mathrm{NMR}$ and ${ }^{13} \mathrm{C}-\mathrm{NMR}$ spectra are reported as Supplementary Material. ESI mass spectra were obtained on a micromass ZMD Waters instrument $\left(30 \mathrm{~V}, 3.2 \mathrm{kV}\right.$, isotope observed $\left.{ }^{79} \mathrm{Br}\right)$. EI mass spectra were recorded on a VG70 70E apparatus. Solvents of reaction were removed under reduced pressure. Silica gel plates (Merck F254) and silica gel 60 (Merck 230-400 mesh) were used for analytical TLC and for column chromatography, respectively. All new compounds gave satisfactory microanalyses $(\mathrm{C}, \mathrm{H}$, halogen, and $\mathrm{N})$. 


\subsection{Synthesis}

2-(4-Bromophenyl)-7-chloroimidazo[2,1-b][1,3]benzothiazole (42a). 2,4'-Dibromoacetophenone (5.0 g, $18 \mathrm{mmol})$ was added to a solution of 2-amino-6-chlorobenzothiazole (41a, $18 \mathrm{mmol})$ in ethanol $(30 \mathrm{~mL})$ and triethylamine $(18 \mathrm{mmol})$. After refluxing $(30 \mathrm{~min}), \mathbf{4 2 a}$ was separated by filtration (yield 30\%; mp 244.0-244.8 ${ }^{\circ} \mathrm{C}$ from ethanol). ${ }^{1} \mathrm{H}-\mathrm{NMR}: \delta 7.62-7.66(3 \mathrm{H}, \mathrm{m}, \mathrm{H}-5$, and HAr); $7.56(1 \mathrm{H}$, dd, $J=8.8$ and $J=1.8 \mathrm{~Hz}, \mathrm{H}-7) ; 7.80\left(2 \mathrm{H}\right.$, part XX' of the system $\left.\mathrm{AA}^{\prime} \mathrm{XX}^{\prime}, \mathrm{HAr}\right) ; 7.98(1 \mathrm{H}, \mathrm{d}, J=8.8 \mathrm{~Hz}$, $\mathrm{H}-8)$; 8.23 (1H, d, $J=1.8 \mathrm{~Hz}, \mathrm{H}-5) ; 8.84$ (1H, s, H-3). ${ }^{13} \mathrm{C}-\mathrm{NMR}: \delta 109.8 ; 114.5 ; 120.1 ; 124.6$; 126.6 ; $126.8 ; 129.1 ; 130.7 ; 131.0 ; 131.7 ; 132.9 ; 145.3 ; 147.7$. EI: $m / z(\%)$ 366-364-362 (M+1 100$) .389-387-385$ $(\mathrm{M}+23)$. HMRS $\left({ }^{79} \mathrm{Br},{ }^{35} \mathrm{Cl}\right.$ isotopes): $\mathrm{m} / z$ calcd for $\mathrm{C}_{15} \mathrm{H}_{8} \mathrm{BrClN}_{2} \mathrm{~S}$ : 361.9280 ; found: 361.9283 .

6-(4-Bromophenyl)imidazo[2,1-b][1,3]thiazole (42b). 2,4'-Dibromoacetophenone (5.0 g, $18 \mathrm{mmol})$ was added to a solution of 2-aminothiazole $(\mathbf{4 1} \mathbf{b}, 18 \mathrm{mmol})$ in $\mathrm{CHCl}_{3}(30 \mathrm{~mL})$ and the mixture was refluxed for $2 \mathrm{~h}$. After cooling, the separated crystals were collected by filtration, added of ethanol $(20 \mathrm{~mL})$ and refluxed with $2 \mathrm{M} \mathrm{HCl}(20 \mathrm{~mL})$ for $2 \mathrm{~h}$. The mixture was treated with saturated $\mathrm{NH}_{4} \mathrm{OH}$ solution until basic and the collected precipitate was crystallized from ethanol to give $\mathbf{4 2 b}$ (yield $81 \%$; mp 180.1-180.8 ${ }^{\circ} \mathrm{C}$; lit. [47] $182{ }^{\circ} \mathrm{C}$, lit. [48] 179-180 $\left.{ }^{\circ} \mathrm{C}\right) .{ }^{1} \mathrm{H}-\mathrm{NMR}: \delta 7.28(1 \mathrm{H}, \mathrm{d}, J=5.3 \mathrm{~Hz}, \mathrm{H}-3)$; 7.57 (2H, part AA' of the system AA'XX', HAr); 7.79 (2H, part XX' of the system AA'XX', HAr); 7.94 $(1 \mathrm{H}, \mathrm{d}, J=5.3 \mathrm{~Hz}, \mathrm{H}-2) ; 8.27$ (1H, s, H-5). ${ }^{13} \mathrm{C}-\mathrm{NMR}: \delta 109.8 ; 113.4 ; 119.8 ; 120.0 ; 126.7 ; 131.5$; 133.5; 145.1; 149.4. HMRS ( ${ }^{79} \mathrm{Br}$ isotope): $\mathrm{m} / z$ calcd for $\mathrm{C}_{11} \mathrm{H}_{7} \mathrm{BrN}_{2} \mathrm{~S}: 277.9513$; found: 277.9514 .

6-(4-Bromophenyl)-3-ethylimidazo[2,1-b][1,3]thiazole (42c). 2,4'-Dibromoacetophenone (5.0 g, $18 \mathrm{mmol})$ was added to a solution of 2-amino-4-ethylthiazole (41c, $18 \mathrm{mmol})$ in acetone $(30 \mathrm{~mL})$ and the mixture was refluxed for $2 \mathrm{~h}$. After cooling, the deposited crystals were collected by filtration, added of ethanol $(20 \mathrm{~mL})$ and refluxed with $2 \mathrm{M} \mathrm{HCl}(20 \mathrm{~mL})$ for $2 \mathrm{~h}$. The mixture was treated with saturated $\mathrm{NH}_{4} \mathrm{OH}$ solution until basic and the collected precipitate was crystallized from ethanol to give 42c (yield 42\%; mp 145.2-146.1 ${ }^{\circ} \mathrm{C}$ ). ${ }^{1} \mathrm{H}-\mathrm{NMR}: \delta 1.30\left(3 \mathrm{H}, \mathrm{t}, J=7.5 \mathrm{~Hz}, \mathrm{CH}_{3}\right) ; 2.80(2 \mathrm{H}$, dq, $\left.J=7.5 \mathrm{~Hz}, J=1.3 \mathrm{~Hz}, \mathrm{CH}_{2}\right) ; 6.94(1 \mathrm{H}, \mathrm{t}, J=1.3 \mathrm{~Hz}, \mathrm{H}-2) ; 7.60(2 \mathrm{H}$, part AA' of the system AA'XX', HAr); $7.81\left(2 \mathrm{H}\right.$, part $\mathrm{XX}^{\prime}$ of the system AA'XX', HAr); $8.43(1 \mathrm{H}, \mathrm{s}, \mathrm{H}-5) .{ }^{13} \mathrm{C}-\mathrm{NMR}: \delta 10.7 ; 20.4$; 107.6; 108.7; 120.1; 126.7; 131.6; 133.6; 133.9;143.8; 148.6. ESI: $m / z 306$ (M); 329 (M + 23). HMRS ( ${ }^{79} \mathrm{Br}$ isotope): $\mathrm{m} / z$ calcd for $\mathrm{C}_{13} \mathrm{H}_{11} \mathrm{BrN}_{2} \mathrm{~S}$ : 305.9826 ; found: 355.9828 .

3-Methyl-6-(2-naphthyl)imidazo[2,1-b][1,3]thiazole (42d). 2-Bromoacetonaphthone (5.23 g, $21.0 \mathrm{mmol})$ was added to a solution of 2-amino-4-methylthiazole $(\mathbf{4 1 d}, 2.0 \mathrm{~g}, 18.0 \mathrm{mmol})$ in acetone $(40 \mathrm{~mL})$ and the mixture was refluxed for $2 \mathrm{~h}$, then the solvent was distilled off. The crude was added of ethanol $(30 \mathrm{~mL})$ and refluxed with $2 \mathrm{M} \mathrm{HCl}(30 \mathrm{~mL})$ for $3 \mathrm{~h}$. The mixture was treated with saturated $\mathrm{NH}_{4} \mathrm{OH}$ solution until basic, the precipitate was collected by filtration, whereas the solution was extracted with $\mathrm{CHCl}_{3}(4 \times 50 \mathrm{~mL})$ and the organic layer was dried on $\mathrm{Na}_{2} \mathrm{SO}_{4}$. Removal of the solvent left a solid which was added to the first portion and purified by flash chromatography (ethyl acetate:petroleum ether $=1: 5 \rightarrow 1: 0 \mathrm{v} / \mathrm{v}$ as eluant) to give the desired compound, which was purified by crystallization from ethanol (yield 66\%; mp 160.8-161.4 ${ }^{\circ} \mathrm{C}$ ). ${ }^{1} \mathrm{H}-\mathrm{NMR}(500 \mathrm{MHz}, \mathrm{DMSO}): \delta 8.40(2 \mathrm{H}, \mathrm{s}, \mathrm{H}-3$ and H-Ar); 8.01 (1H, pd, H-Ar); 7.93 (2H, pd, H-Ar); 7.89 (1H, pd, H-Ar); 7.51 (1H, pt, H-Ar); 7.47 (1H, pt, H-Ar); 6.92 (1H, s, H-6); 2.45 (3H, s, $\left.\mathrm{CH}_{3}\right) .{ }^{13} \mathrm{C}-\mathrm{NMR}$ (125 MHz, DMSO): $\delta 148.8 ; 146.2 ; 133.3$; 
$132.2 ; 131.8 ; 128.2 ; 128.1 ; 127.8 ; 127.6 ; 126.4 ; 123.5 ; 122.6 ; 108.6 ; 107.1 ; 12.8 . \mathrm{EI}: \mathrm{m} / z(\%) 264$ (100); 153 (10); 69 (14). ESI: $m / z 287$ (M + 23). HMRS: $m / z$ calcd for $\mathrm{C}_{16} \mathrm{H}_{12} \mathrm{~N}_{2} \mathrm{~S}: 264.07212$; found: 264.0722 .

General Procedure for the synthesis of 5-nitrosoimidazo[2,1-b][1,3]thiazole derivatives 43a-d.

A solution of sodium nitrite $(8.7 \mathrm{mmol})$ in water $(10 \mathrm{~mL})$ was added, under cooling and stirring, to a solution of the appropriate imidazo[2,1-b][1,3]thiazole $42(4 \mathrm{mmol})$ in acetic acid $(20 \mathrm{~mL})$. After 6-30 $\mathrm{h}$ (TLC analysis) and a new addition of sodium nitrite $(8.7 \mathrm{mmol}$ ) at room temperature (or at $50{ }^{\circ} \mathrm{C}$ in the instance of 43a), the mixture was neutralized with $2 \mathrm{M} \mathrm{NaOH}$ and the green precipitate was collected and crystallized from ethanol.

2-(4-Bromophenyl)-7-chloro-3-nitrosoimidazo[2,1-b][1,3]benzothiazole $\quad$ (43a). $\quad$ Yield: $\quad 90 \%$; mp 256.4-257.1 ${ }^{\circ} \mathrm{C} .{ }^{1} \mathrm{H}-\mathrm{NMR}: \delta 7.73(1 \mathrm{H}, \mathrm{dd}, J=9.1 \mathrm{~Hz}, J=2.1 \mathrm{~Hz}, \mathrm{H}-6) ; 7.85$ (2H, part AA' of the system AA'XX', HAr); $8.36(1 \mathrm{H}, \mathrm{ps}, \mathrm{H}-8) ; 8.43\left(2 \mathrm{H}\right.$, part $\mathrm{XX}^{\prime}$ of the system AA'XX', HAr); 8.76 $(1 \mathrm{H}, \mathrm{d}, J=9.1 \mathrm{~Hz}, \mathrm{H}-5)$. HMRS $\left({ }^{79} \mathrm{Br},{ }^{35} \mathrm{Cl}\right.$ isotopes): $m / z$ calcd for $\mathrm{C}_{15} \mathrm{H}_{7} \mathrm{BrClN}_{3} \mathrm{OS}$ : 390.9182 ; found: 390.9184.

6-(4-Bromophenyl)-5-nitrosoimidazo[2,1-b][1,3]thiazole (43b). Yield: 90\%; mp 218.0-219.0 ${ }^{\circ} \mathrm{C}$ (lit. [49] $\left.220{ }^{\circ} \mathrm{C}\right) .{ }^{1} \mathrm{H}-\mathrm{NMR}: \delta 7.67(1 \mathrm{H}, \mathrm{d}, J=4.3 \mathrm{~Hz}, \mathrm{H}-3) ; 7.83(2 \mathrm{H}$, part AA' of the system AA'XX', HAr); $8.46(1 \mathrm{H}, \mathrm{d}, J=5.3 \mathrm{~Hz}, \mathrm{H}-2) ; 8.4\left(2 \mathrm{H}\right.$, part $\mathrm{XX}^{\prime}$ of the system AA'XX', HAr). ${ }^{13} \mathrm{C}-\mathrm{NMR}: \delta$ $120.6 ; 121.4 ; 125.6 ; 130.7 ; 131.3 ; 132.2 ; 156.2 ; 156.39 ; 159.3$. HMRS ( ${ }^{79} \mathrm{Br}$ isotope): $\mathrm{m} / z$ calcd for $\mathrm{C}_{11} \mathrm{H}_{6} \mathrm{BrN}_{3} \mathrm{OS}: 306.9415$; found: 306.9415 .

6-(4-Bromophenyl)-3-ethyl-5-nitrosoimidazo[2,1-b][1,3]thiazole (43c). Yield: 76\%; mp 188.0-190.0 ${ }^{\circ} \mathrm{C}$. ${ }^{1} \mathrm{H}-\mathrm{NMR}: \delta 1.06\left(3 \mathrm{H}, \mathrm{t}, J=7.3 \mathrm{~Hz}, \mathrm{CH}_{3}\right) ; 3.03\left(2 \mathrm{H}, \mathrm{q}, J=7.3 \mathrm{~Hz}, J=1.3 \mathrm{~Hz}, \mathrm{CH}_{2}\right) ; 7.19$ (1H, s, H-2); $7.79\left(2 \mathrm{H}\right.$, part $\mathrm{AA}^{\prime}$ of the system $\left.\mathrm{AA}^{\prime} \mathrm{XX}, \mathrm{HAr}\right) ; 8.32\left(2 \mathrm{H}\right.$, part $\mathrm{XX}^{\prime}$ of the system $\left.\mathrm{AA}^{\prime} \mathrm{XX}^{\prime}, \mathrm{HAr}\right)$. ${ }^{13}$ C-NMR: $\delta$ 13.4; 23.7; 112.9; 125.23; 130.9; 131.9; 132.0; 138.8; 156.1;159.9; 161.3. ESI: $m / z 334$ $(\mathrm{M}) ; 357(\mathrm{M}+23)$. HMRS $\left({ }^{79} \mathrm{Br}\right.$ isotope): $\mathrm{m} / z$ calcd for $\mathrm{C}_{13} \mathrm{H}_{10} \mathrm{BrN}_{3} \mathrm{OS}$ : 334.9728; found: 334.9729 .

3-Methyl-6-(2-naphthyl)-5-nitrosoimidazo[2,1-b][1,3]thiazole (43d). Yield: 90\%; mp 216.4-217.2 ${ }^{\circ} \mathrm{C}$. ${ }^{1} \mathrm{H}-\mathrm{NMR}$ (500 MHz, DMSO): $\delta 9.01$ (1H, s, H-Ar); 8.50 (1H, pd, H-Ar); 8.11 (1H, pd, H-Ar); 8.08 (1H, pd, H-Ar); 8.01 (1H, pd, H-Ar); 7.65 (1H, pt, H-Ar); 7.61 (1H, pt, H-Ar); 7.18 (1H, s, H-6); 2.60 $\left(3 \mathrm{H}, \mathrm{s}, \mathrm{CH}_{3}\right) .{ }^{13} \mathrm{C}-\mathrm{NMR}(125 \mathrm{MHz}, \mathrm{DMSO}): \delta 161.4 ; 160.5 ; 156.5 ; 133.9 ; 133.1 ; 132.6 ; 130.8 ; 129.2$; $129.1 ; 128.2 ; 127.8 ; 126.8 ; 126.4 ; 113.7 ; 17.0$. EI: $\mathrm{m} / z$ (\%) 293 (1000); 292 (30); 278 (21); 277 (91); 276 (84); 266 (22); 264 (53); 264 (33); 262 (26); 244 (29); 239 (20); 238 (37); 179 (26); 164 (34); 153 (47); 139 (25); 127 (33); 72 (30); 71 (39). ESI: $m / z 316$ (M + 23). HMRS: $m / z$ calcd for $\mathrm{C}_{16} \mathrm{H}_{11} \mathrm{~N}_{3} \mathrm{OS}$ : 293.06228; found: 293.0623 .

General procedure for the synthesis of hydroxy[1,2,4] oxadiazolo[3,4-c][1,4]thiazinones 30, 34, 35, and 37. A suspension of the appropriate nitroso derivative $43(3 \mathrm{mmol})$ in ethanol $(25 \mathrm{~mL})$ was refluxed under stirring with $2 \mathrm{M} \mathrm{HCl}(2.5 \mathrm{~mL})$ for $2-4 \mathrm{~h}$. Removal of the solvent left a solid which was purified by flash-chromatography to give the desired compound. 
from toluene. ${ }^{1} \mathrm{H}-\mathrm{NMR}: \delta$ 7.59-7.66 (3H, m, H-6 or H-8 and part AA' of the system AA'XX', HAr); 7.70-7.75 $(3 \mathrm{H}, \mathrm{m}, \mathrm{H}-8$ or $\mathrm{H}-6$ and part XX' of the system AA'XX', HAr); $8.21(1 \mathrm{H}, \mathrm{d}, J=8.8 \mathrm{~Hz}$, $\mathrm{H}-9) ; 8.70\left(1 \mathrm{H}\right.$, s exch., OH). ${ }^{13} \mathrm{C}-\mathrm{NMR}: \delta 77.8 ; 119.4 ; 123.1 ; 125.3 ; 127.7 ; 128.3 ; 128.6 ; 129.1$; 131.1; 131.3; 135.3; 155.0; 155.3. EI: $m / z$ (\%) 368-366 (7), 229-227 (13); 185-183 (100), 157-155 (30). HMRS ( ${ }^{79} \mathrm{Br}$ isotope): $m / z$ calcd for $\mathrm{C}_{15} \mathrm{H}_{8} \mathrm{BrClN}_{2} \mathrm{O}_{3}$ : 409.9127 ; found: 409.9128.

8-Hydroxy-5-methyl-8-(2-naphthyl)-8H-[1,2,4]oxadiazolo[3,4-c][1,4]thiazin-3-one (34). Eluant mixture: ethyl acetate-petroleum ether $=1: 4 \mathrm{v} / \mathrm{v}$. Yield: $45 \%$; mp $155.6-156.7{ }^{\circ} \mathrm{C}$ from ethanol. ${ }^{1} \mathrm{H}-\mathrm{NMR}$ (400 MHz, DMSO): $\delta 8.36(1 \mathrm{H}, \mathrm{s}, \mathrm{OH}) ; 8.25$ (1H, s, H-Ar); 8.04-7.94 (3H, m, H-Ar); 7.70 (1H, pd, $\mathrm{H}-\mathrm{Ar}) ; 7.62-7.55$ (2H, m, H-Ar); 6.26 (1H, s, H-6); 2.44 (3H, s, CH3). ${ }^{13} \mathrm{C}-\mathrm{NMR}(100 \mathrm{MHz}, \mathrm{DMSO})$ : $\delta 155.8 ; 155.0 ; 134.3 ; 132.9 ; 132.1 ; 128.6 ; 128.4 ; 127.8 ; 127.5 ; 127.1 ; 126.7 ; 126.3 ; 124.7 ; 103.5$; 77.0; 16.7. EI: m/z (\%) 312 (5); 173 (11); 172 (92); 156 (13); 155 (99); 128 (16); 127 (199); 126 (19); 81 (21); 77 (12); 69 (42). ESI: $m / z 335(\mathrm{M}+23)$. HMRS: $m / z$ calcd for $\mathrm{C}_{16} \mathrm{H}_{12} \mathrm{~N}_{2} \mathrm{O}_{3} \mathrm{~S}: 312.05687$; found: 312.0565 .

8-(4-Bromophenyl)-8-hydroxy-8H-[1,2,4]oxadiazolo[3,4-c][1,4]thiazin-3-one (35). Eluant mixture: ethyl acetate- $n$-hexane $=1: 2 \mathrm{v} / \mathrm{v}$. Yield: $45 \%$; mp $164.4-164.5^{\circ} \mathrm{C}$ from toluene. ${ }^{1} \mathrm{H}-\mathrm{NMR}$ : X $6.60(1 \mathrm{H}$, $\mathrm{d}, J=7.5 \mathrm{~Hz}, \mathrm{H}-6) ; 7.26(1 \mathrm{H}, \mathrm{d}, J=7.5 \mathrm{~Hz}, \mathrm{H}-5) ; 7.62(2 \mathrm{H}$, part AA' of the system AA'XX', HAr); $7.68\left(2 \mathrm{H}\right.$, part $\mathrm{XX}^{\prime}$ of the system AA'XX', HAr); $8.44(1 \mathrm{H}, \mathrm{s}$ exch., $\mathrm{OH}) .{ }^{13} \mathrm{C}-\mathrm{NMR}: \delta 77.0 ; 109.8$; 116.2 ; $122.8 ; 129.3 ; 131.2$; 136.4; 154.1; 154.7. EI: $m / z$ (\%) 326-328 (M+, 3$), 226-224$ (10), 185-183 (100), 157-155 (45); 147 (15); 91(25); 81 (19). ESI: $m / z 349$ (M + 23). HMRS ( ${ }^{79} \mathrm{Br}$ isotope): $m / z$ calcd for $\mathrm{C}_{11} \mathrm{H}_{7} \mathrm{BrN}_{2} \mathrm{O}_{3} \mathrm{~S}$ : 325.9362 ; found: 325.9361 .

8-(4-Bromophenyl)-5-ethyl-8-hydroxy-8H-[1,2,4]oxadiazolo[3,4-c][1,4]thiazin-3-one (37). Eluant mixture: ethyl acetate-petroleum ether $=1: 3 \mathrm{v} / \mathrm{v}$. Yield: $50 \% ; \mathrm{mp} 153.5-155.2{ }^{\circ} \mathrm{C}$ from $\mathrm{EtOH} / \mathrm{H}_{2} \mathrm{O}$. ${ }^{1} \mathrm{H}-\mathrm{NMR}: \delta 1.13\left(3 \mathrm{H}, \mathrm{t}, J=7.3 \mathrm{~Hz}, \mathrm{CH}_{3}\right) ; 2.87\left(2 \mathrm{H}, \mathrm{qd}, J=7.3 \mathrm{~Hz}, J=1.0 \mathrm{~Hz}, \mathrm{CH}_{2}\right) ; 6.23(1 \mathrm{H}, \mathrm{t}$, $J=1.0 \mathrm{~Hz}, \mathrm{H}-6) ; 7.58\left(2 \mathrm{H}\right.$, part $\mathrm{AA}^{\prime}$ of the system AA'XX', HAr); 7.67 (2H, part XX' of the system AA'XX', HAr); 8.25 (1H, s exch., OH). ${ }^{13} \mathrm{C}-\mathrm{NMR}: \delta 12.0 ; 23.0 ; 76.2 ; 104.3 ; 122.7 ; 129.2 ; 131.1$; 134.2; 136.3; 154.6; 155.8. ESI: $m / z 354(\mathrm{M}-1)$. HMRS $\left({ }^{79} \mathrm{Br}\right.$ isotope): $m / z$ calcd for $\mathrm{C}_{13} \mathrm{H}_{11} \mathrm{BrN}_{2} \mathrm{O}_{3} \mathrm{~S}$ : 353.9674; found: 353.9677 .

General procedure for the synthesis of alkoxy-[1,2,4]oxadiazolo[3,4-c][1,4]thiazinones 31, 36, 46, and 47. A suspension of the appropriate hemithioacetal $(\mathbf{3 8}, \mathbf{3 5}, \mathbf{4 4}$, or $\mathbf{4 5}$, respectively; $1.3 \mathrm{mmol})$ in dry toluene $(40 \mathrm{~mL})$ was refluxed for $4 \mathrm{~h}$ under stirring with $13.0 \mathrm{mmol}$ of the opportune alcohol and in the presence of a catalytic amount of $p$-toluenesulfonic acid (ca. $0.5 \mathrm{mmol}$ ). The reaction mixture was cooled at room temperature and washed with a saturated aqueous solution of $\mathrm{NaHCO}_{3}$. The organic layer was separated and the aqueous layer was extracted with toluene $(3 \times 40 \mathrm{~mL})$. The collected organic phases were dried on $\mathrm{Na}_{2} \mathrm{SO}_{4}$. Removal of the solvent left a solid which was purified by flash-chromatography to give the desired compound.

4-(4-Bromophenyl)-4-isopropoxy-4H-[1,2,4]oxadiazolo[3,4-c][1,4]benzothiazin-1-one (31). Eluant mixture: ethyl acetate-petroleum ether $=1: 4 \mathrm{v} / \mathrm{v}$. Yield: $14 \% ; \mathrm{mp} 178.1-178.7{ }^{\circ} \mathrm{C}$ from ethanol. ${ }^{1} \mathrm{H}-\mathrm{NMR}: \delta 0.87\left(3 \mathrm{H}, \mathrm{d}, J=6.1 \mathrm{~Hz}, \mathrm{CH}_{3}\right) ; 0.90\left(3 \mathrm{H}, \mathrm{d}, J=6.1 \mathrm{~Hz}, \mathrm{CH}_{3}\right) ; 3.93(1 \mathrm{H}$, sept, $J=6.1 \mathrm{~Hz}$, $\mathrm{CH}) ; 7.43(1 \mathrm{H}, \mathrm{t}, J=7.7 \mathrm{~Hz}, \mathrm{H}-7$ or $\mathrm{H}-8)$; $7.56(1 \mathrm{H}, \mathrm{t}, J=7.5 \mathrm{~Hz}, \mathrm{H}-8$ or H-7); 7.66 (3H, part AA' of 
the system AA'XX', HAr and H-6 or H-9); 7.70 (2H, part XX' of the system AA'XX', HAr); $8.16(1 \mathrm{H}$, $\mathrm{d}, J=8.0 \mathrm{~Hz}, \mathrm{H}-9$ or H-6). ${ }^{13} \mathrm{C}-\mathrm{NMR}: \delta 23.3 ; 23.5 ; 70.2 ; 83.4 ; 118.3 ; 121.7 ; 124.0 ; 127.9 ; 128.6$; 129.6; 129.9; 130.2; 131.7; 133.0; 154.5; 155.1. EI: $m / z(\%) 418-420\left(\mathrm{M}^{+}, 8\right), 235$ (28), 193 (100), 185-183 (48), 157-155 (17). ESI: $m / z 441(\mathrm{M}+23)$. HMRS $\left({ }^{79} \mathrm{Br}\right.$ isotope): $\mathrm{m} / z$ calcd for $\mathrm{C}_{18} \mathrm{H}_{15} \mathrm{BrN}_{2} \mathrm{O}_{3} \mathrm{~S}: 417.9987$; found: 419.9989.

8-(4-Bromophenyl)-8-ethoxy-8H-[1,2,4] oxadiazolo[3,4-c][1,4]thiazin-3-one (36). Eluant mixture: ethyl acetate- $n$-hexane $=1: 5 \mathrm{v} / \mathrm{v}$. Yield: $67 \%$; mp 127.1-127.7 ${ }^{\circ} \mathrm{C}$ from toluene. ${ }^{1} \mathrm{H}-\mathrm{NMR}: \delta 1.17(3 \mathrm{H}, \mathrm{t}$, $\left.J=6.9 \mathrm{~Hz}, \mathrm{CH}_{3}\right) ; 3.42-3.48\left(1 \mathrm{H}, \mathrm{m}, \mathrm{CH}_{2}\right) ; 3.52-3.58\left(1 \mathrm{H}, \mathrm{m}, \mathrm{CH}_{2}\right) ; 6.60(1 \mathrm{H}, \mathrm{d}, J=7.3 \mathrm{~Hz}, \mathrm{H}-6)$; $7.25(1 \mathrm{H}, \mathrm{d}, J=7.3 \mathrm{~Hz}, \mathrm{H}-5) ; 7.58$ (2H, part AA' of the system AA'XX', HAr); 7.71 (2H, part XX' of the system AA'XX', HAr). ${ }^{13} \mathrm{C}^{\prime} \mathrm{NMR}: \delta 14.6 ; 61.1 ; 82.6 ; 108.9 ; 116.7 ; 123.3 ; 129.5 ; 131.7 ; 133.7$; 152.2; 154.5. EI: $m / z(\%)$ 356-354 (M+, 79), 312-310 (15), 311-309 (100), 267-265 (11); 187 (12), 185-183 (95), 157-155 (70); 143 (28); 76 (28); 75 (27). ESI: $m / z 377$ (M + 23). HMRS ( ${ }^{79} \mathrm{Br}$ isotope): $m / z$ calcd for $\mathrm{C}_{13} \mathrm{H}_{11} \mathrm{BrN}_{2} \mathrm{O} 3 \mathrm{~S}: 353.9671$; found: 353.9674 .

8-(2-Bromoethoxy)-8-(4-bromophenyl)-5-methyl-8H-[1,2,4]oxadiazolo[3,4-c][1,4]thiazin-3-one (46). Eluant mixture: ethyl acetate-petroleum ether $=1: 2 \mathrm{v} / \mathrm{v}$. Yield: $55 \%$; mp $141.8-142.7{ }^{\circ} \mathrm{C}$ from ethanol. ${ }^{1} \mathrm{H}-\mathrm{NMR}: \delta 2.40\left(3 \mathrm{H}, \mathrm{s}, \mathrm{CH}_{3}\right) ; 3.64-3.68\left(3 \mathrm{H}, \mathrm{m}, \mathrm{CH}_{2} \mathrm{Br}\right.$ and $\left.\mathrm{CHO}\right) ; 3.88-3.92(1 \mathrm{H}, \mathrm{m}, \mathrm{CHO}) ; 6.22$ $(1 \mathrm{H}, \mathrm{s}, \mathrm{H}-6) ; 7.60(2 \mathrm{H}$, part AA' of the system AA'XX', HAr); $7.72(2 \mathrm{H}$, part XX' of the system AA'XX', HAr). ${ }^{13}$ C-NMR: $\delta 16.6 ; 31.3 ; 64.9 ; 82.0 ; 103.2 ; 123.6 ; 129.7 ; 129.8 ; 131.8 ; 132.3 ; 153.8 ; 154.7$.

8-(2-Bromoethoxy)-8-(4-chlorophenyl)-5-methyl-8H-[1,2,4]oxadiazolo[3,4-c][1,4]thiazin-3-one Eluant mixture: ethyl acetate-petroleum ether $=1: 2 \mathrm{v} / \mathrm{v}$. Yield: $58 \% ; \mathrm{mp} 111.2-112.0{ }^{\circ} \mathrm{C}$ from ethanol. ${ }^{1} \mathrm{H}-\mathrm{NMR}: \delta 2.40\left(3 \mathrm{H}, \mathrm{s}, \mathrm{CH}_{3}\right) ; 3.64-3.70\left(3 \mathrm{H}, \mathrm{m}, \mathrm{CH}_{2} \mathrm{Br}\right.$ and $\left.\mathrm{OCH}\right) ; 3.88-3.93(1 \mathrm{H}, \mathrm{m}, \mathrm{OCH}) ; 6.23(1 \mathrm{H}$, s, H-6); 7.59 (2H, part AA' of the system AA'XX', HAr); $7.68(2 \mathrm{H}$, part XX' of the system AA'XX', HAr). ${ }^{13}$ C-NMR: $\delta 16.5 ; 31.3 ; 64.9 ; 81.9 ; 103.2 ; 128.9 ; 129.5 ; 129.8 ; 131.9 ; 134.8 ; 153.8 ; 154.6$.

General procedure for the synthesis of 8-(4-halophenyl)-5-methyl-8-(2-piperidin-1-ylethoxy)-8H$[1,2,4]$ oxadiazolo[3,4-c] [1,4]thiazin-3-ones 32 and 33. A solution of the appropriate acetal (46 or 47, respectively; $1.0 \mathrm{mmol})$ in piperidine $(1.5 \mathrm{~mL})$ and triethylamine $(0.4 \mathrm{~mL})$ was refluxed for $1 \mathrm{~h}$ under stirring. The reaction mixture was cooled at room temperature and treated with water $(10 \mathrm{~mL})$, then ethyl acetate $(10 \mathrm{~mL})$ was added. The organic layer was separated and the aqueous layer was extracted with ethyl acetate $(3 \times 15 \mathrm{~mL})$. The collected organic phases were dried on $\mathrm{Na}_{2} \mathrm{SO}_{4}$. Removal of the solvent left a solid which was purified by flash-chromatography to give the desired compound.

8-(4-Bromophenyl)-5-methyl-8-(2-piperidin-1-ylethoxy)-8H-[1,2,4]oxadiazolo[3,4-c][1,4]thiazin-3-one (32). Eluant mixture: ethyl acetate-petroleum ether $=1: 1 \mathrm{v} / \mathrm{v}$. Yield: $30 \%$; mp $128.6-129.8{ }^{\circ} \mathrm{C}$ from $n$-hexane. ${ }^{1} \mathrm{H}-\mathrm{NMR}: \delta 1.32-1.40\left(2 \mathrm{H}, \mathrm{m}, \mathrm{CH}_{2}\right) ; 1.43-1.52\left(4 \mathrm{H}, \mathrm{m}, 2 \mathrm{xCH}_{2}\right) ; 2.20-2.38(4 \mathrm{H}, \mathrm{m}$, $\left.2 \mathrm{xNCH}_{2}\right) ; 2.40\left(3 \mathrm{H}, \mathrm{s}, \mathrm{CH}_{3}\right) ; 2.42-2.47\left(2 \mathrm{H}, \mathrm{m}, \mathrm{NCH}_{2}\right) ; 3.37-3.42(1 \mathrm{H}, \mathrm{m}, \mathrm{OCH}) ; 3.55-3.60(1 \mathrm{H}, \mathrm{m}$, $\mathrm{OCH}) ; 6.23(1 \mathrm{H}, \mathrm{s}, \mathrm{H}-6) ; 7.62\left(2 \mathrm{H}\right.$, part $\mathrm{AA}^{\prime}$ of the system $\left.\mathrm{AA}^{\prime} \mathrm{XX}^{\prime}, \mathrm{HAr}\right) ; 7.70\left(2 \mathrm{H}\right.$, part $\mathrm{XX}^{\prime}$ of the system AA'XX', HAr). ${ }^{13} \mathrm{C}^{\prime} \mathrm{NMR}: \delta 16.4 ; 23.9 ; 25.5 ; 54.3 ; 57.3 ; 62.9 ; 82.0 ; 103.4 ; 123.3 ; 129.7$; 129.8; 131.6; 132.6; 154.1; 154.6. EI: $\mathrm{m} / z$ (\%) 253-255 (55), 207 (17), 204 ( 22); 105 (100). ESI: $\mathrm{m} / \mathrm{z}$ $476(\mathrm{M}+23)$. 
8-(4-Chlorophenyl)-5-methyl-8-(2-piperidin-1-ylethoxy)-8H-[1,2,4] oxadiazolo[3,4-c][1,4]thiazin-3-one (33). Eluant mixture: ethyl acetate-petroleum ether $=1: 1 \mathrm{v} / \mathrm{v}$. Yield: $28 \%$; mp $112.5-113.0{ }^{\circ} \mathrm{C}$ from $n$-hexane. ${ }^{1} \mathrm{H}-\mathrm{NMR}: \delta 1.31-1.39\left(2 \mathrm{H}, \mathrm{m}, \mathrm{CH}_{2}\right) ; 1.42-1.51\left(4 \mathrm{H}, \mathrm{m}, 2 \mathrm{xCH}_{2}\right) ; 2.20-2.38(4 \mathrm{H}, \mathrm{m}$, $\left.2 \mathrm{xNCH}_{2}\right) ; 2.41\left(3 \mathrm{H}, \mathrm{s}, \mathrm{CH}_{3}\right) ; 2.43-2.47\left(2 \mathrm{H}, \mathrm{m}, \mathrm{NCH}_{2}\right) ; 3.38-3.43(1 \mathrm{H}, \mathrm{m}, \mathrm{OCH}) ; 3.55-3.61(1 \mathrm{H}, \mathrm{m}$, $\mathrm{OCH}) ; 6.23(1 \mathrm{H}, \mathrm{s}, \mathrm{H}-6) ; 7.57\left(2 \mathrm{H}\right.$, part $\mathrm{AA}^{\prime}$ of the system $\left.\mathrm{AA}^{\prime} \mathrm{XX}^{\prime}, \mathrm{HAr}\right) ; 7.69$ (2H, part XX' of the system AA'XX', HAr). ${ }^{13} \mathrm{C}-\mathrm{NMR}: \delta 16.5 ; 23.9 ; 25.6 ; 54.3 ; 57.3 ; 62.9 ; 81.9 ; 103.4 ; 128.7 ; 129.5$; 129.7; 132.2; 134.6; 154.2; 154.6. ESI: $m / z 430(\mathrm{M}+23)$.

\subsection{Functional Assays}

The pharmacological profile of all compounds was derived on guinea-pig isolated left and right atria to evaluate their inotropic and/or chronotropic effects, respectively, and on $\mathrm{K}^{+}$-depolarized $(80 \mathrm{mM})$ guinea-pig vascular (aortic strips) and nonvascular [ileum longitudinal smooth muscle (GPILSM)] to assess the calcium antagonist activity. Compounds were checked at increasing doses to evaluate: (i) the percent decrease of developed tension on isolated left atrium driven at $1 \mathrm{~Hz}$ (negative inotropic activity); (ii) the percent decrease in atrial rate on spontaneously beating right atrium (negative chronotropic activity); and (iii) the percent inhibition of calcium-induced contraction on $\mathrm{K}^{+}$-depolarized aortic strips and GPILSM (vascular and non-vascular relaxant activity, respectively). Details were already described in [12]. Data were analyzed using Student's $t$-test and are presented as mean \pm SEM [28]. Since the analyzed compounds were added in cumulative manner, the difference between the control and the experimental values at each concentration were tested for a $p$ value $<0.05$. The potency of drugs defined as $\mathrm{EC}_{50}, \mathrm{EC}_{30}$ and $\mathrm{IC}_{50}$ was evaluated from log concentration-response curves (Probit analysis using Litchfield and Wilcoxon [28] or GraphPad Prism ${ }^{\circledR}$ software [50,51]) in the appropriate pharmacological preparations.

\subsection{Electrophysiology Experiments}

\subsubsection{Tail Main Artery Dissection}

This investigation conforms to the Guide for the Care and Use of Laboratory Animals published by the U.S. National Institutes of Health (NIH Publication No. 85-23, revised 1996), and the animal protocols used were reviewed and approved by the Animal Care and Ethics Committee of the Università di Siena, Italy (08-02-2012). Male Wistar rats (300-400 g, Charles River Italia, Calco, Italy) were anesthetized with a mixture of $\operatorname{Ketavet}^{\circledR}\left(30 \mathrm{mg} \cdot \mathrm{kg}^{-1}\right.$ ketamine; Intervet, Aprilia, Italy) and Xilor ${ }^{\circledR}$ (8 $\mathrm{mg} \cdot \mathrm{kg}^{-1}$ xylazine; Bio 98, San Lazzaro, Italy), decapitated and exsanguinated. The tail was cut immediately, cleaned of skin and placed in physiological solution (namely external solution, containing in mM: $130 \mathrm{NaCl}, 5.6 \mathrm{KCl}, 10 \mathrm{HEPES}, 20$ glucose, $1.2 \mathrm{MgCl}_{2} \cdot 6 \mathrm{H}_{2} \mathrm{O}$, and $5 \mathrm{Na}$-pyruvate; $\mathrm{pH}$ 7.4). The tail main artery was dissected free of its connective tissue.

\subsubsection{Cell Isolation Procedure for IBa Recordings}

Smooth muscle cells were freshly isolated from the tail main artery under the following conditions: a 5-mm long piece of artery was incubated at $37{ }^{\circ} \mathrm{C}$ for $40-45 \mathrm{~min}$ in $2 \mathrm{~mL}$ of $0.1 \mathrm{mM} \mathrm{Ca}^{2+}$ external solution containing $20 \mathrm{mM}$ taurine (prepared by replacing $\mathrm{NaCl}$ with equimolar taurine), $1.35 \mathrm{mg} \cdot \mathrm{mL}^{-1}$ 
collagenase (type XI), $1 \mathrm{mg} \cdot \mathrm{mL}^{-1}$ soybean trypsin inhibitor, and $1 \mathrm{mg} \cdot \mathrm{mL}^{-1}$ bovine serum albumin, which was gently bubbled with a $95 \% \mathrm{O}_{2}-5 \% \mathrm{CO}_{2}$ gas mixture to gently stir the enzyme solution, as previously described [52]. After isolation, cell suspension was stored in $0.05 \mathrm{mM} \mathrm{Ca}^{2+}$ external solution containing $20 \mathrm{mM}$ taurine and $0.5 \mathrm{mg} \cdot \mathrm{mL}^{-1}$ bovine serum albumin, at $4{ }^{\circ} \mathrm{C}$ under normal atmosphere.

\subsubsection{Whole-Cell Patch Clamp Recordings}

Cells were continuously superfused with external solution containing $0.1 \mathrm{mM} \mathrm{Ca}^{2+}$ and $30 \mathrm{mM}$ TEA using a peristaltic pump (LKB 2132, Bromma, Sweden), at a flow rate of $400 \mu \mathrm{L} \cdot \mathrm{min}^{-1}$. The conventional whole-cell patch-clamp method [53] was employed to voltage-clamp smooth muscle cells. Recording electrodes were pulled from borosilicate glass capillaries (WPI, Berlin, Germany) and fire-polished to obtain a pipette resistance of 2-5 $\mathrm{M} \Omega$ when filled with internal solution [containing, in mM: $100 \mathrm{CsCl}, 10$ Hepes, 11 EGTA, $1 \mathrm{CaCl}_{2}$ (pCa 8.4), $2 \mathrm{MgCl}_{2} \cdot 6 \mathrm{H}_{2} \mathrm{O}, 5$ Na-pyruvate, 5 succinic acid, 5 oxaloacetic acid, $3 \mathrm{Na} 2-\mathrm{ATP}$, and 5 phosphocreatine; $\mathrm{pH}$ was adjusted to 7.4 with $\mathrm{CsOH}$ ]. $\mathrm{Ca}^{2+}$ concentration was calculated using the computer programme EqCal (BioSoft, Cambridge, UK) by taking into account $\mathrm{pH}$ and $\mathrm{Mg}^{2+}$ concentration, as described by Fabiato \& Fabiato [54]. An Axopatch 200B patch-clamp amplifier (Molecular Devices Corporation, Sunnyvale, CA, USA) was used to generate and apply voltage pulses to the clamped cells and record the corresponding membrane currents. At the beginning of each experiment, the junction potential between the pipette and bath solution was electronically adjusted to zero. Current signals, after compensation for whole-cell capacitance and series resistance (between 70\%-80\%), were low-pass filtered at $1 \mathrm{kHz}$ and digitized at $3 \mathrm{kHz}$ prior to being stored on the computer hard disk. Electrophysiological responses were tested at room temperature $\left(20-22{ }^{\circ} \mathrm{C}\right)$.

\subsubsection{IBa Recordings}

Cells used in this study expressed both LTCC and T-type $\mathrm{Ca}^{2+}$ channels [55]. IBa was always recorded in external solution containing $30 \mathrm{mM}$ TEA as well as $5 \mathrm{mM} \mathrm{Ba}^{2+}$. Current was elicited with 250-ms clamp pulses $(0.067 \mathrm{~Hz})$ to $-40 \mathrm{mV}$ or $0 \mathrm{mV}$ from a $\mathrm{V}_{\mathrm{h}}$ of $-80 \mathrm{mV}$. Data were collected once the current amplitude had been stabilised (usually 7-10 min after the whole-cell configuration had been obtained). Under these conditions $\mathrm{I}_{\mathrm{Ba}(\mathrm{L})}$ did not run down during the following $40 \mathrm{~min}$ [56]. $\mathrm{K}^{+}$ currents were blocked with $30 \mathrm{mM}$ TEA in the external solution and $\mathrm{Cs}^{+}$in the internal solution. Current values were corrected for leakage and residual outward currents using $10 \mu \mathrm{M}$ nifedipine,

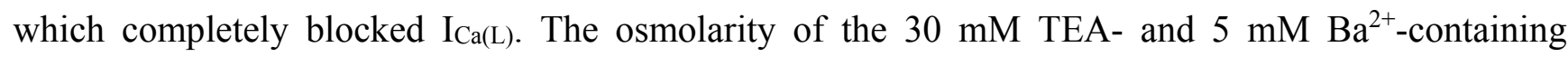
external solution (320 mosmol) and that of the internal solution (290 mosmol; [57]) were measured with an osmometer (Osmostat OM 6020, Menarini Diagnostics, Florence, Italy). Following control measurements, each cell was exposed to cumulative concentration of a drug by flushing through the experimental chamber recording solution containing the drug. Compounds $\mathbf{3 0}$ and 32, dissolved directly in DMSO, were diluted at least 1000 times prior to use. The resulting concentrations of DMSO (below $0.1 \%, \mathrm{v} / \mathrm{v}$ ) failed to alter the response of the preparations. Acquisition and analysis of data were accomplished by using pClamp 8.2.0.232 and 9.2.1.8 software (Molecular Devices Corporation), respectively, and GraphPad Prism version 5.04 (GraphPad Software Inc., San Diego, CA, USA). Data 
are reported as mean $\pm \mathrm{SEM}$; $\mathrm{n}$ is the number of cells analysed (indicated in parentheses), isolated from at least 3 animals.

\subsection{Binding Studies}

\subsubsection{Cardiomyocytes Isolation}

All animal care and experimental procedures complied with the International guidelines for the Care and Use of Laboratory Animals and were approved by the Animal Care and Ethics Committee of the Università di Siena, Italy. Single cardiac myocytes (CM) were isolated from male Sprague-Dawley rats (Charles River Italia, Como, Italy), injected with 500 U/100 g b.w. heparin i.p., anaesthetized (i.p.) with a mixture of Ketavet ${ }^{\circledR}\left(30 \mathrm{mg} \cdot \mathrm{kg}^{-1}\right.$ ketamine; Intervet, Aprilia, Italy) and Xilor ${ }^{\circledR}\left(8 \mathrm{mg} \cdot \mathrm{kg}^{-1}\right.$ xylazine; Bio 98, San Lazzaro, Italy), decapitated, and bled. After thoracotomy, the heart was rapidly removed, mounted on a micro-Langendorff apparatus, and perfused for $20 \mathrm{~min}$ at $37{ }^{\circ} \mathrm{C}$ with a nominally $\mathrm{Ca}^{2+}$-free solution (low $\mathrm{Ca}^{2+}$ solution, LCS) of the following composition (mM): $120 \mathrm{NaCl}$, $10 \mathrm{KCl}, 10 \mathrm{HEPES}, 10$ glucose, $1.2 \mathrm{MgCl}_{2}, 1.2 \mathrm{KH}_{2} \mathrm{PO}_{4}, 5 \mathrm{Na}$-pyruvate, and 20 taurine at $\mathrm{pH} 7.2$, equilibrated with $95 \% \mathrm{O}_{2} / 5 \% \mathrm{CO}_{2}$. The solution was then quickly changed to LCS complemented with $0.9 \mathrm{mg} / \mathrm{mL}$ of collagenase Type I (Sigma Chimica, Milan, Italy), $0.05 \mathrm{mg} / \mathrm{mL}$ of Dispase I (Roche Gmbh, Penzbeg, Germany), and $1.5 \mathrm{mg} / \mathrm{mL}$ of acid-free bovine serum albumin (Sigma Chimica, Milan, Italy) for 10 to $15 \mathrm{~min}$. When the heart was soft, perfusion was stopped, and the tissue was chopped into small pieces and gently stirred in fresh LCS at room temperature. The cardiomyocytes that appeared in the supernatant were purified by centrifugation $(5 \mathrm{~min}$ at $800 \mathrm{~g})$ and frozen at $-80{ }^{\circ} \mathrm{C}$ until use. Pooled cells derived from at least three animals have been used for each binding experiment. Protein concentrations were estimated by using the method of Bradford with BSA as the standard.

\subsection{2. $\left[{ }^{3} \mathrm{H}\right]$ Diltiazem Binding Assays}

Aliquots of defrozen rat CM $(200 \mu \mathrm{g})$ were incubated with ligands in $50 \mathrm{mM}$ Tris buffer ( $\mathrm{pH} 7.4)$ at $25{ }^{\circ} \mathrm{C}$ for $90 \mathrm{~min}$ in a final volume of $0.2 \mathrm{~mL}$. For heterologous competition curves, fixed amounts of the tracer $(5 \mathrm{nM})$ were displaced by increasing concentrations of several unlabeled ligands $(0.1 \mathrm{nM}-100 \mu \mathrm{M})$. Incubation was terminated by rapid filtration on Whatman GF/B glass fiber filters (presoaked for at least $1 \mathrm{~h}$ in polyethyleneimmine $0.5 \%$ ) and washed three times with $3 \mathrm{~mL}$ of ice-cold wash buffer. The filters were then placed in scintillation vials, $5 \mathrm{~mL}$ of liquid scintillation added, and the radioactivity was determined by liquid scintillation using Perkin Elmer TRI-CARB 1900 TR instrument (Perkin-Elmer Life Science, Boston, MA, USA). Nonspecific binding was defined by means of $100 \mu \mathrm{M}$ unlabeled diltiazem. All of the experiments were always run in triplicate.

\subsection{Multidrug Resistance Studies}

The potentiation of antiproliferative activity of oxadiazolothiazinones 25-27 was evaluated by the MTT test using an oxadiazolothiazinone concentration causing per se 5\% inhibition of cell proliferation, as described in reference [13]. 


\subsection{Molecular Modelling of Calcium Channels Blockers}

The version 2.0 of the software FLAP [58] was used to develop all the in silico models described. Several features were used, including: database generation, molecular alignment, 3D-QSAR, pharmacophore generation, and docking of the pharmacophore. Details are reported below.

Database: A database of oxadiazolothiazinones was created with the following options: up to 50 conformers; minimum RMSD between two conformers set to $0.1 \AA$; GRID probes DRY, O and N1.

Alignment. An automatic alignment was obtained for the 29 molecules of the dataset (see Supplementary, Table S1) that are from the present paper and from references $[11,12,26]$. The procedure selects the two compounds with the highest similarity (based on molecular graphs) and aligns them. Then, the alignment of all the other molecules is run iteratively, with the set of templates increased of one molecule after each run. Among the criteria to build the molecular graphs, atom numbers were used. The alignment consists of the superimposition of the common substructure, followed by a geometrical relaxation, repeated several times in order to achieve an optimal solution (number of conformers set to 10).

3D-QSAR variables. The block of the probe $\mathrm{O}$ and the blocks for the pseudofields POSITIVE (POS) and NEGATIVE (NEG) were excluded. This was carried out by selecting the option Pretreatment, excluding the mentioned blocks, and assigning weight $=1.0$ to the other blocks that were used (probes H, DRY, N1, pseudofields HYD, DON, ACC, AROM, HAL).

3D-QSAR regression method. An algorithm named IVPLS (Iterative Variable Simplification-Partial Least Squares) was used. This is a modified PLS in which a dimension-wide variable simplification is carried out.

Pharmacophore generation. The 3D structures of 25, 28, 29, 48 (P1 in reference [36]), 49 (B3 in reference [36]), 50 (M8 in reference [36]), and diltiazem were imported in FLAP as described above (Database), then up to 30 additional conformations were generated on-the-fly by FLAPpharm, that filters the conformations in order to keep the most pharmacophorically similar ones, and then performs a pruned tree search to find common alignment models; this was done with the option "Quick model". The best model was selected; it is a pseudomolecule with a score of 0.958 .

Docking of the LTCC pharmacophore. The file with the coordinates of a single snapshot of the homology model of L-type $\mathrm{Ca}^{2+}$ channel with diltiazem was received from Prof B. Zhorov [43]. The homology model was imported into FLAP, and the selected pharmacophoric pseudomolecule docked into the channel site using the "pseudo high" option; in other words the atom-centred pseudofields of the pharmacophore were matched to the GRID MIFs of the channel, with the "high strictness" setting. The higher strictness filters the model points and fields to leave those that are common to $60 \%$ or more of the aligned input molecules. The pharmacophoric pseudomolecule was docked into the protein and the first solution of the docking analysis by pose, according to the "Global Product Score", was taken as result of the pharmacophore-docking.

\subsection{Molecular Modelling of P-glycoprotein Inhibitors}

PGP Docking simulation. All the protein target structures were built by homology using the software MODELLER [59]. The model utilized as target in our simulations was the NBD2 domain built by 
homology using the coordinates of the human NBD1 domain (PDB code 2CBZ) as a template [60]. Each moiety was docked to the protein model using the software AutoDock 3.05 with the macromolecule considered as a rigid body and the ligands being flexible. In the case of NBD2 domain the grid was extended over the whole protein. A grid spacing of $0.375 \AA$ was used to build affinity maps for all the atoms present, and an electrostatic map. The correct positioning of the ligands within the active site cleft we validated using a second docking program, GOLD (CCDC, Cambridge, UK) which also allowed us the calculation of a fitness function (Goldscore) in order to confirm our findings obtained by the with AutoDock software

\section{Conclusions}

For this special issue on in silico drug design and in silico screening we have reported the case study of oxadiazolothiazinones. We describe their synthesis through a ring-into-ring conversion by applying the Cusmano-Ruccia reaction. When specifically decorated at position- 8 with an OR group (with $\mathrm{R}=$ alkyl chain) and a substituted phenyl, this scaffold exerts a negative inotropic activity on guinea-pig heart, and inhibits human P-glycoprotein.

In the past, we have studied the ability of this series of oxadiazolothiazinones to decrease the inotropy, developed a QSAR model, and used the most potent oxadiazolothiazinone as a template for ligand-based virtual screening. Here, we enlarge the chemical decorations of the oxadiazolothiazinone scaffold, and present for the first time the synthesis and in vitro data for 11 new derivatives. According to data for guinea-pig isolated left and right atria, we found two compounds with negative inotropic activity (with submicromolar potency) and two with negative chronotropic activity. We also tested all the molecules on vascular and nonvascular smooth muscle: every compound except $\mathbf{3 0}$ and $\mathbf{3 4}$ is inactive in relaxing vascular smooth muscle. As regards the activity relaxing the nonvascular smooth muscle, all compounds except $\mathbf{2 5}$ were slightly active.

We investigated two compounds, $\mathbf{3 0}$ and 32, in more detail, under experimental conditions that allow for the identification of blockers of LTCC. High $\mathrm{K}^{+}$-induced contraction of aorta rings, in fact, is the result of an increased $\mathrm{Ca}^{2+}$ influx through LTCC and is specifically inhibited by $\mathrm{Ca}^{2+}$-antagonists. Both compounds antagonize high $\mathrm{K}^{+}$-induced contraction in a concentration-dependent manner, interpretable as a consequence of the blockade of LTCC. We also studied the binding at the benzothiazepine-binding site: the complex interaction exerted by 32 might reflect a positive allosteric modulation at the diltiazem binding site, as already observed for 25 [36].

With the functional data we have developed a new 3D-QSAR model for negative inotropic potency: with very recent in silico techniques, we have built a quantitative in silico model which will be used to design further derivatives, and obtained a pharmacophore that may be useful for screening. The new model is currently in use for the prediction of the activity of further derivatives.

A key role in the biologically relevant interactions, observed with different protein systems (ion channel and P-glycoprotein), is played by the oxadiazolone moiety: the distribution of the molecular electrostatic potential has shown that the two oxygen atoms generate a region of significant interaction with a positive charge. In the case of ion channels, given the presence of the positively charged calcium ions in the transmembrane protein LTCC, we hypothesize the formation of a ternary complex between the molecule (oxadiazolothiazinone), the ion $\left(\mathrm{Ca}^{2+}\right)$ and the protein (LTCC): we elaborated and 
verified this hypothesis by means of pharmacophore generation (based on a set of diverse molecules that we identified as active against LTCC) and through the docking of the pharmacophore into a homology model of the protein. In the case of P-glycoprotein, given the presence of positively charged residues (Arg) in the binding pocket, we hypothesize a strong interaction of the oxadiazolothiazinone moiety: we supported this hypothesis by calculating the Molecular Electrostatic Potential and observing a significant complementarity between the two partners, oxadiazolothiazinone and P-glycoprotein.

\section{Supplementary Materials}

Supplementary materials can be accessed at: http://www.mdpi.com/1420-3049/19/10/16543/s1.

\section{Acknowledgments}

This research was supported by funds from MIUR and University of Bologna. E.C. thanks B. Zhorov for the use of the coordinates of the homology model for LTCC. The authors thank Alessandro Casoni for animal care.

\section{Author Contributions}

Roberta Budriesi (RB) coordinated the functional experiments, drafted the manuscript and coordinated the work; Pierfranco Ioan (PI) and Matteo Micucci (MM) carried out the functional experiments; Alberto Chiarini (AC) revised the manuscript; Barbara Cosimelli (BC) and Elda Severi (ES) synthesized the molecules; Domenico Spinelli (DS) designed the synthesis and coordinated the work; Camillo Rosano (CR) and Maurizio Viale (MV) carried out the experimental tests and the docking into P-glycoprotein; Fabio Fusi (FF) and Simona Saponara (SS) carried out the electrophysiology experiments; Maria Frosini (MF) and Rosanna Matucci (RM) carried out the binding experiments; Massimo Baroni (MB) and Simon Cross (SC) developed the FLAP algorithms that are presented here (3D-QSAR and pharmacophore-docking); Emanuele Carosati (EC) performed the in silico models, drafted the manuscript and coordinated the work; RB, EC, and DS participated in the conception and design of the study. All the authors provided assistance in drafting the paper, read and approved the final manuscript.

\section{Conflicts of Interest}

The authors declare no conflict of interest.

\section{References}

1. Trost, B.M., Fleming, I., Eds. Comprehensive Organic Synthesis; Pergamon: New York, NY, USA, 1991.

2. Rees, C.W., Katritzky, A.R., Eds. Heterocyclic Chemistry: The Structure, Reactions, Synthesis and Uses of Heterocyclic Compounds; Pergamon: New York, NY, USA, 1984.

3. Rees, C.W., Katritzky, A.R., Scriven, E.F.V., Eds. Comprehensive Heterocyclic Chemistry II. A Review of the Literature 1982-1995; Pergamon: Oxford, UK, 1996. 
4. Katritzky, A.R., Ramsden, C., Scriven, E.F.V., Taylor, R., Eds. Comprehensive Heterocyclic Chemistry III. A Review of the Literature 1995-2007; Elsevier: London, UK, 2008.

5. Ruccia, M.; Vivona, N.; Spinelli, D. Mononuclear heterocyclic rearrangements. Adv. Heterocycl. Chem. 1981, 29, 141-169.

6. Vivona, N.; Buscemi, S.; Frenna, V.; Cusmano, G. Ring transformation of five-membered heterocycles. Adv. Heterocycl. Chem. 1993, 56, 49-154.

7. Pozharskii, A.F., Soldatenkov, A.T., Katritzky, A.R., Eds. Heterocycles in Life and Society: An Introduction to Heterocyclic Chemistry and Biochemistry and the Role of Heterocycles in Science, Technology, Medicine and Agriculture; John Wiley \& Sons: Chichester, England, 1997. pp. 1-314.

8. Bird, C.W. Heteroaromaticity, 5, A unified aromaticity index. Tetrahedron 1992, 48, 335-340.

9. Balaban, A.T.; Oniciu, D.C.; Katritzky, A.R. Aromaticity as a Cornerstone of Heterocyclic Chemistry. Chem. Rev. 2004, 104, 2777-2812.

10. Spinelli, D.; Mugnoli, A.; Andreani, A.; Rambaldi, M.; Frascati, S. A new ring transformation: Conversion of $6-p$-chlorophenyl-3-methyl-5-nitrosoimidazo[2,1- $b]$ thiazole into 8-p-chlorophenyl-8-hydroxy-5-methyl-3-oxo-1,2,4-oxadiazolo[3,4-c] [1,4]thiazine by the action of mineral acids. J. Chem. Soc. Chem. Commun. 1992, 1394-1395.

11. Budriesi, R.; Cosimelli, B.; Ioan, P.; Lanza, C.Z.; Spinelli, D.; Chiarini, A. Cardiovascular characterization of $[1,4]$ thiazino[3,4-c][1,2,4] oxadiazol-3-one-derivatives: Selective myocardial calcium channel modulators. J. Med. Chem. 2002, 45, 3475-3481.

12. Budriesi, R.; Carosati, E.; Chiarini, A.; Cosimelli, B.; Cruciani, G.; Ioan, P.; Spinelli, D.; Spisani, R. A New Class of Selective Myocardial Calcium Channel Modulators. 2. The Role of the Acetal Chain in Oxadiazol-3-one Derivatives. J. Med. Chem. 2005, 48, 2445-2456.

13. Viale, M.; Cordazzo, C.; Cosimelli, B.; de Totero, D.; Castagnola, P.; Aiello, C.; Severi, E.; Petrillo, G.; Cianfriglia, M.; Spinelli, D. Inhibition of MDR1 Activity in vitro by a Novel Class of Diltiazem Analogues: Towards New Candidates. J. Med. Chem. 2009, 52, 259-266.

14. Rosano, C.; Viale, M.; Cosimelli, B.; Severi, E.; Gangemi, R.; Ciogli, A.; de Totero, A.; Spinelli, D. ABCB1 Structural Models, Molecular Docking and Synthesis of New Oxadiazolothiazin-3-ones Inhibitors. ACS Med. Chem. Lett. 2013, 4, 694-698.

15. Cusmano, S.; Ruccia, M. Sui nitrosoimidazoli. Azione dell'acido cloridrico sul 4-(o-5)nitroso-25-(o-4)difenilimidazolo. Nota IV. Gazz. Chim. Ital. 1955, 85, 1686-1697.

16. Cusmano, S.; Ruccia, M. Sui nitrosoimidazoli. I nitrosoderivati del 5(o-4)-fenil- e del 2-metil-5(o4)-fenilimidazolo e loro comportamento reattivo. Nota VI. Gazz. Chim. Ital. 1958, 88, 463-481.

17. Cosimelli, B.; Guernelli, S.; Spinelli, D.; Buscemi, S.; Frenna, V.; Macaluso, G. On the Synthesis and Reactivity of the Z-2,4-Dinitrophenylhydrazone of 5-Amino-3-benzoyl-1,2,4-oxadiazole. J. Org. Chem. 2001, 66, 6124-6129.

18. Andreani, A.; Billi, R.; Cosimelli, B.; Mugnoli, A.; Rambaldi, M.; Spinelli, D. Ring-ring interconversion: The rearrangement of 6-(4-chlorophenyl)-3-methyl-5-nitrosoimidazo[2,1$b][1,3]$ thiazole into 8-(4-chlorophenyl)-8-hydroxy-5-methyl-8H-[1,4]thiazino[3,4-c][1,2,4]oxadiazol3-one. Elucidation of the reaction product through spectroscopic and X-ray crystal structure analysis. J. Chem. Soc. Perkin Trans. 2 1997, 2, 2407-2410. 
19. Billi, R.; Cosimelli, B.; Spinelli, D.; Rambaldi, M. Ring-ring interconversions. Part 2. Effect of the Substituent on the Rearrangement of 6-Aryl-3-methyl-5-nitrosoimidazo[2,1-b][1,3]thiazoles into 8-Aryl-8-hydroxy-5-methyl-8H-[1,4]thiazino[3,4-c][1,2,4]oxadiazol-3-ones. A Novel Class of Potential Antitumor Agents. Tetrahedron 1999, 55, 5433-5440.

20. Billi, R.; Cosimelli, B.; Leoni, A.; Spinelli, D. Ring-ring Interconversions. Part 3. On the effect of the substituents on the thiazole moiety in the ring-opening/ring-closing reactions of nitrosoimidazo[2,1-b][1,3]thiazoles with hydrochloric acid. J. Heterocycl. Chem. 2000, 37, 875-878.

21. Cosimelli, B.; Frenna, V.; Rambaldi, M.; Severi, E.; Spinelli, D. On the reactivity of nitrosoimidazoles with acids (the Cusmano-Ruccia reaction): A continuous source of new ring-into-ring conversion. Tetrahedron Lett. 2014, 55, 1488-1490.

22. Billi, R.; Cosimelli, B.; Spinelli, D.; Andreani, A.; Leoni, A. Ring-ring Interconversions of Nitrosoimidazoles. The Effect of Some Condensed Six-membered Rings on the Reactivity. Tetrahedron 2000, 56, 6527-6532.

23. Budriesi, R.; Cosimelli, B.; Ioan, P.; Carosati, E.; Ugenti, M.P.; Spisani, R. Diltiazem Analogues: The Last Ten Years on Structure Activity Relationships. Curr. Med. Chem. 2007, 14, 279-287.

24. Buckley, M.M.T.; Grant, S.M.; Goa, K.L.; McTavish, D.; Sorkin, E.M. Diltiazem: A reappraisal of its pharmacological properties and therapeutic use. Drugs 1990, 39, 757-806.

25. Triggle, D.J. Calcium channel antagonists: Clinical uses-Past, present and future. Biochem. Pharmacol. 2007, 74, 1-9.

26. Carosati, E.; Ioan, P.; Barrano, G.B.; Caccamese, S.; Cosimelli, B.; Devlin, F.J.; Severi, E.; Spinelli, D.; Superchi, S.; Budriesi, R. Synthesis and Absolute Configuration Determination of New Oxadiazolothiazinones Active as L-Type Calcium Channel Blockers. Eur. J. Med. Chem. 2014, submitted.

27. Bottoni, A.; Calvaresi, M.; Ciogli, A.; Cosimelli, B.; Mazzeo, G.; Pisani, L.; Severi, E.; Spinelli, D.; Superchi, S. Selective and Practical Oxidation of Sulfides to Diastereopure Sulfoxides: A Combined Experimental and Computational Investigation. Adv. Synth. Catal. 2013, 355, 191-202.

28. Tallarida, R.J.; Murray, R.B. Manual of Pharmacologic Calculations with Computer Programs, 2nd ed.; Springer-Verlag: New York, NY, USA, 1987.

29. Karaki, H.; Ozaki, H.; Hori, M.; Mitsui-Saito, M.; Amano, K.-I.; Harada, K.-I.; Miyamoto. S.; Nakazawa, H.; Won, K.-J.; Sato, K. Calcium movements, distribution, and function in smooth muscle. Pharmacol. Rev. 1997, 49, 157-230.

30. Irvine, R.F. Inositol phosphates and $\mathrm{Ca}^{2+}$ entry: Toward a proliferation or a simplification? FASEB J. 1992, 6, 3085-3091.

31. Van Breemen, C.; Saida, K. Cellular mechanisms regulating $\left[\mathrm{Ca}^{2+}\right] \mathrm{i}$ smooth muscle. Annu. Rev. Physiol. 1989, 51, 315-329.

32. Kuriyama, H.; Kitamura, K.; Nabata, H. Pharmacological and physiological significance of ion channels and factors that modulate them in vascular tissues. Pharmacol. Rev. 1995, 47, 387-573.

33. Mugnai, P.; Durante, M.; Sgaragli, G.; Saponara, S.; Paliuri, G.; Bova, S.; Fusi, F. L-type Ca ${ }^{2+}$ channel current characteristics are preserved in rat tail artery myocytes after one-day storage. Acta Physiol. 2014, 211, 334-345.

34. McDonald, T.F.; Pelzer, S.; Trautwein, W.; Pelzer, D.J. Regulation and modulation of calcium channels in cardiac, skeletal, and smooth muscle cells. Physiol. Rev. 1994, 74, 365-507. 
35. Timin, E.N.; Berjukow, S.; Hering, S. Concepts of state-dependent pharmacology of calcium channels. In Calcium Channel Pharmacology; McDonough, S.I., Ed.; Kluwer Academic/Plenum Publishers: New York, NY, USA, 2004; pp. 1-19.

36. Carosati, E.; Cruciani, G.; Chiarini, A.; Budriesi, R.; Ioan, P.; Spisani, R.; Spinelli, D.; Cosimelli, B.; Fusi, F.; Frosini, M.; et al. Calcium Channel Antagonists Discovered by a Multidisciplinary Approach. J. Med. Chem. 2006, 49, 5206-5216.

37. Cruciani, G.; Watson, K.A. Comparative molecular field analysis using GRID force-field and GOLPE variable selection methods in a study of inhibitors of glycogen phosphorylase b. J. Med. Chem. 1994, 37, 2589-2601.

38. Molecular Discovery Website. Available online: http://www.moldiscovery.com (accessed on 1 June 2014).

39. Baroni, M.; Cruciani, G.; Sciabola, S.; Perruccio, F.; Mason, J.S. A Common Reference Framework for Analyzing/Comparing Proteins and Ligands. Fingerprints for Ligands and Proteins (FLAP): Theory and Application. J. Chem. Inf. Model. 2007, 47, 279-294.

40. Cross, S.; Baroni, M.; Carosati, E.; Benedetti, P.; Clementi, S. FLAP: GRID Molecular Interaction Fields in Virtual Screening. Validation using the DUD Data Set. J. Chem. Inf. Model. 2010, 50, 1442-1450.

41. Lindgren, F. Third Generation PLS. Some Elements and Applications; Solfjädern Offset AB: Umeå, Sweden, 1994.

42. Cross, S.; Baroni, M.; Goracci, L.; Cruciani, G. GRID-Based Three-Dimensional Pharmacophores I: FLAPpharm, a Novel Approach for Pharmacophore Elucidation. J. Chem. Inf. Model. 2012, 52, 2587-2598.

43. Tikhonov, D.B.; Zhorov, B.S. Benzothiazepines in L-type Calcium Channel: Insights from Molecular Modeling. J. Biol. Chem. 2008, 283, 17594-17604.

44. Pettersen, E.F.; Goddard, T.D.; Huang, C.C.; Couch, G.S.; Greenblatt, D.M.; Meng, E.C.; Ferrin, T.E. UCSF Chimera-A Visualization System for Exploratory Research and Analysis. J. Comput. Chem. 2004, 25, 1605-1612.

45. Cornell, W.D.; Cieplak, P.; Bayly, C.I.; Gould, I.R.; Merz, K.M., Jr.; Ferguson, D.M.; Spellmeyer, D.C.; Fox, T.; Caldwell, J.W.; Kollman, P.A. A Second Generation Force Field for the Simulation of Proteins, Nucleic Acids, and Organic Molecules. J. Am. Chem. Soc. 1995, 117, 5179-5197.

46. Prijs, B.; Ostertag, J.; Erlenmeyer, H. Nitrothiazole compounds. II. Helv. Chim. Acta 1947, 30, 2110-2113.

47. Buu-Hoi, N.P.; Xuong, N.D.; THU-CUC, T. Reaction of $\omega$-bromoacetophenones with 2-aminothiazole and 2-aminobenzothiazoles. Bull. Soc. Chim. Fr. 1966, 4, 1277-1279.

48. Aggarval, R.; Sumran, G. Hypervalent Iodine in the Synthesis of Bridgehead heterocycles: A Facile Route to the Synthesis of 6-Arylimidazo[2,1-b]thiazoles Using [Hydroxy(tosyloxy)iodo]benzene. Synth. Commun. 2006, 36, 875-879.

49. Von Pyl, T.; Wünschm, K.-H.; Beyer, H. Nitrosierung und Azokupplung von 6-Phenyl-imidazo[2,1-b]thiazolen. Liebigs Ann. Chem. 1962, 657, 108-113.

50. Motulsky, H.J.; Christopoulos, A. Fitting Models to Biological Data Using Linear and Non Linear Regression, 2003. Available online: http://www.graphpad.com (accessed on 10 May 2010). 
51. Motulsky, H.J. Prism 5 Statistics Guide; GraphPad Software Inc.: San Diego, CA, USA, 2007. Available online: http://www.graphpad.com (accessed on 10 May 2010).

52. Fusi, F.; Saponara, S.; Gagov, H.; Sgaragli, G.P. 2,5-Di-t-butyl-1,4-benzohydroquinone (BHQ) inhibits vascular L-type $\mathrm{Ca}^{2+}$ channel via superoxide anion generation. Br. J. Pharmacol. 2001, 133, 988-996.

53. Hamill, O.P.; Marty, A.; Neher, E.; Sakmann, B.; Sigworth, F.J. Improved patch-clamp techniques for high-resolution current recording from cells and cell-free membrane patches. Pflüg. Arch. 1981, 391, 85-100.

54. Fabiato, A.; Fabiato, F. Calculator programs for computing the composition of the solutions containing multiple metals and ligands used for experiments in skinned muscle cells. J. Physiol. 1979, 75, 463-505.

55. Petkov, G.V.; Fusi, F.; Saponara, S.; Gagov, H.; Sgaragli, G.P.; Boev, K.K. Characterization of voltage-gated calcium currents in freshly isolated smooth muscle cells from rat tail main artery. Acta Physiol. Scand. 2001, 173, 257-265.

56. Fusi, F.; Sgaragli, G.; Ha, L.M.; Cuong, N.M.; Saponara, S. Mechanism of osthole inhibition of vascular Cav1.2 current. Eur. J. Pharmacol. 2012, 680, 22-27.

57. Stansfeld, C.; Mathie, A. Recording membrane currents of peripheral neurones in short-term culture. In Electrophysiology. A Practical Approach; Wallis, D.I., Ed.; IRL Press: Oxford, UK, 1993; pp. 3-28.

58. The Version 2.0 of the Software FLAP Is Distributed by Molecular Discovery Ltd. Available online: http://www.moldiscovery.com (accessed on 1 September 2014).

59. Sali, A.; Blundell, T.L. Comparative protein modelling by satisfaction of spatial restraints. J. Mol. Biol. 1993, 234, 779-815.

60. Ramaen, O.; Leulliot, N.; Sizun, C.; Ulryck, N.; Pamlard, O.; Lallemand, J.Y.; Tilbeurgh, H.; Jacquet, E. Structure of the human multidrug resistance protein 1 nucleotide binding domain 1 bound to $\mathrm{Mg}^{2+} / \mathrm{ATP}$ reveals a non-productive catalytic site. J. Mol. Biol. 2006, 359, 940-949.

Sample Availability: Samples of the compounds are available from the authors.

(C) 2014 by the authors; licensee MDPI, Basel, Switzerland. This article is an open access article distributed under the terms and conditions of the Creative Commons Attribution license (http://creativecommons.org/licenses/by/4.0/). 